\title{
Solvent-, and catalysts-free immobilization of tannic acid and polyvinylpyrrolidone onto PMMA surface by DBD plasma
}

\begin{tabular}{|r|l|}
\hline Journal: & Plasma Processes and Polymers \\
\hline Manuscript ID & ppap.201600202.R1 \\
\hline Wiley - Manuscript type: & Full Paper \\
\hline Complete List of Authors: & Klébert, Szilvia; Institute of Materials and Environmental \\
& $\begin{array}{l}\text { Chemistry Research Centre for Natural Sciences HAS, Department of } \\
\text { Plasma Chemistry } \\
\text { Károly, Zoltán; Institute of Materials and Environmental } \\
\text { Chemistry Research Centre for Natural Sciences HAS , Department of } \\
\text { Plasma Chemistry } \\
\text { Késmárki, András; Institute of Materials and Environmental } \\
\text { Chemistry Research Centre for Natural Sciences HAS , Department of } \\
\text { Plasma Chemistry } \\
\text { Domján, Attila; 2Institute of Organic Chemistry, Research Centre for } \\
\text { Natural Sciences, Hungarian Academy of Sciences } \\
\text { Mohai, Miklós; Institute of Materials and Environmental } \\
\text { Chemistry Research Centre for Natural Sciences HAS , Department of } \\
\text { Plasma Chemistry } \\
\text { Keresztes, Zsófia; Institute of Materials and Environmental } \\
\text { Chemistry Research Centre for Natural Sciences HAS, Functional } \\
\text { Interfaces Research Group } \\
\text { Kutasi, Kinga; Wigner Research Centre for Physics of the Hungarian } \\
\text { Academy of Sciences, Institute for Solid State Physics and Optics }\end{array}$ \\
\hline Keywords: & \begin{tabular}{l} 
\\
\hline
\end{tabular} \\
\hline
\end{tabular}


Solvent-, and catalysts-free immobilization of tannic acid and polyvinylpyrrolidone onto PMMA surface by DBD plasma

Szilvia Klébert ${ }^{1}$, Zoltán Károly ${ }^{1}$, András Késmárki ${ }^{1,3}$, Attila Domján ${ }^{2}$, Miklós Mohai ${ }^{1}$, Keresztes $Z$ Zsófia $^{1}$, Kinga Kutasi ${ }^{4}$

${ }^{1}$ Institute of Materials and Environmental Chemistry, Research Centre for Natural Sciences, Hungarian Academy of Sciences, H-1117 Magyar tudósok krt 2, Budapest, Hungary

${ }^{2}$ Institute of Organic Chemistry, Research Centre for Natural Sciences, Hungarian Academy of Sciences, H-1117 Magyar tudósok krt 2, Budapest, Hungary

${ }^{3}$ Laboratory of Plastics and Rubber Technology, Department of Physical Chemistry and Materials Science, Budapest University of Technology and Economics, H-1521 Budapest, Hungary

${ }^{4}$ Wigner Research Centre for Physics of the Hungarian Academy of Sciences, Institute for Solid State Physics and Optics, Konkoly Thege M. út 29-33, H-1121 Budapest, Hungary

Abstract

Polyvinylpyrrolidone (PVP) and tannic acid (TAN) macromolecules were attached to polymethyl methacrylate (PMMA) surface in a two-step approach in order to establish a tailored tissue-friendly surface layer. First PMMA surface was activated by an air diffuse coplanar surface barrier discharge plasma and subsequently coated with these macromolecules. PVP and TAN which has antibacterial effects are widely used in food and drug industry, however have never applied for polymer surface modification. Throughout characterization measurements confirm that during plasma treatment oxygen containing functional groups $(-\mathrm{OH},-\mathrm{C}=\mathrm{O},-\mathrm{COOH})$ incorporate in the surface. 1HNMR spectroscopy verified the strong $\mathrm{H}$-bonds between PVP and TAN, which rendered the layer-by-layer as- 
sembly of these molecules. The roughness increased considerably during plasma treatment, which can promote the further reactions with organic molecules.

Keywords: DBD plasma, surface treatment, PMMA, surface composition, functionalization of polymers

\section{Introduction}

Polymers are extensively applied in many areas of medicine due to its bioinert characteristic and its ease of tailoring their physical and chemical properties for a given purpose. Polymethyl methacrylate (PMMA) is also widely used in many areas of life $[1,2]$ due to its superior chemical and physical properties. It has excellent light transmittance, low density and mechanical properties (impact strength, toughness) superior to glass [3]. The ease of processing and low production cost also contributes to their widespread application. Its biocompatibility makes PMMA highly attractive material in medicine either as drug delivery agent, eye- and contact glasses, orthopedic surgery or dentistry, but especially as intraocular lenses [4,5]. One of the main concerns of their use as implant is its hydrophobic nature. Hydrophobic surfaces have strong tendency to adsorb proteins such as cells and bacteria, often irreversibly $[6,7]$.

Many researches have been carried out to overcome this shortcoming of polymers including PMMA. A common approach to make the surface more hydrophilic is to modify the surface chemistry. Due to the chemical inertness of the polymeric materials their surface modification means that first they shall undergo surface activation before subsequent covalent functionalisation (Fig.1.). It was found that a hydrophilic surface created by surface modification and formation of new functional groups on the surface by oxygen plasma treatment greatly inhibited bacterial adhesion to PMMA surface [8]. The hydrophilic properties, however, usually does not last long due to the ageing effect of such treatment [9]. The speed of ageing is affected by several operating factors of the treatment, includ- 
ing the applied voltage, exposure time, temperature, etc. To counteract ageing of the activated surface different molecules are attached or grafted to the surface to establish the desired properties for longer term. Zang et al. immobilized heparin ( $\mathrm{Hp}$ ) and polyethylene glycol (PEG) onto the pretreated PMMA surface by Ar plasma irradiation [10] and attained improved hydrophilicity and antithrombogenicity. Diamino-PEG was attached onto PMMA by hydrolysis or aminolysis method by Patel et al. [11] to take advantage of the cell adhesion resistance of PEG. HEMA as a nontoxic, non-immunogenic and non-antigenic biocompatible material was also grafted onto previously functionalized surface both by Wei [12] and by Gilliam et al. [13]. Surface functionalization was performed by low temperature atmospheric plasma process and by dielectric barrier discharges at relatively high pressure, respectively. As a result, PMMA intraocular lenses exhibited suppressed proliferation of cells.

Over the past decades numerous methods have been developed for surface modification of polymers, such as wet chemical methods [14-16], chemical vapour deposition [17], UV irradiation [18,19], several varieties of plasma treatments [20-24], etc. [25]. Among plasma treatments the nonequilibrium atmospheric pressure dielectric barrier discharge (DBD) plasma processing has become one of the most promising techniques due to the combination of its advantages, including fast, environmental friendly, solvent-free processing, low operation and maintenance costs [26] considering atmospheric operation version. DBD is typically obtained between two parallel electrodes separated by a gap of some millimetres and excited by alternating current voltage with frequency in the range of $1-20 \mathrm{kHz}$ [27]. The diversity of DBD configurations regarding the geometrical shape and operating parameters is remarkable. With coplanar electrode arrangement a surface discharge can be ignited, which allows the treatment of large flat areas. In this configuration the electrodes of opposite polarity are embedded within a plane dielectric material usually made of glass, quartz or ceramics. The plasma treatment affects only the topmost layer $(\mathrm{cc} .10 \mathrm{~nm})[23,28$,$] of the surface without using$ chemicals or solvents and producing chemical waste. Surface activation can be carried out by various gases, which result in different functional groups. Noble gas non-thermal plasmas usually activate the surface with establishing radicals, while air, $\mathrm{O}_{2}, \mathrm{~N}_{2}, \mathrm{NH}_{3}$, and $\mathrm{CF}_{4}$ gases could generate $\mathrm{O}, \mathrm{N}, \mathrm{H}$, and $\mathrm{F}$ 
containing functional groups on the surface. The introduced groups $\left(\mathrm{C}=\mathrm{O},-\mathrm{COOH},-\mathrm{OH},-\mathrm{NH}_{2}\right.$, etc.) could be subsequently used to bind other molecules to attain the desired properties $[12,29,30]$.

In this work we present the surface modification of PMMA by Diffuse Coplanar Surface Dielectric Barrier Discharge (DCSDBD) operated in atmospheric pressure air, which was successfully employed in our earlier work for enhancing the hydrophilicity and thus the wettability of polytetrafluoroethylene (PTFE) [31]. The aim of surface modification is to endow antimicrobial properties of the PMMA surface. Unlike earlier studies we attain this by attaching selected macromolecules including polyvinylpyrrolidone (PVP) and tannic acid (TAN) onto the activated surface. While both molecules are biocompatible, the tannic acid also exhibits strong antimicrobial effect $[32,33]$, which may be of a great practical use in intraocular lens production. PVP alone could increase the hydrophilic properties of the surface [34] but its primary role is to improve the attachment of TAN to PMMA.

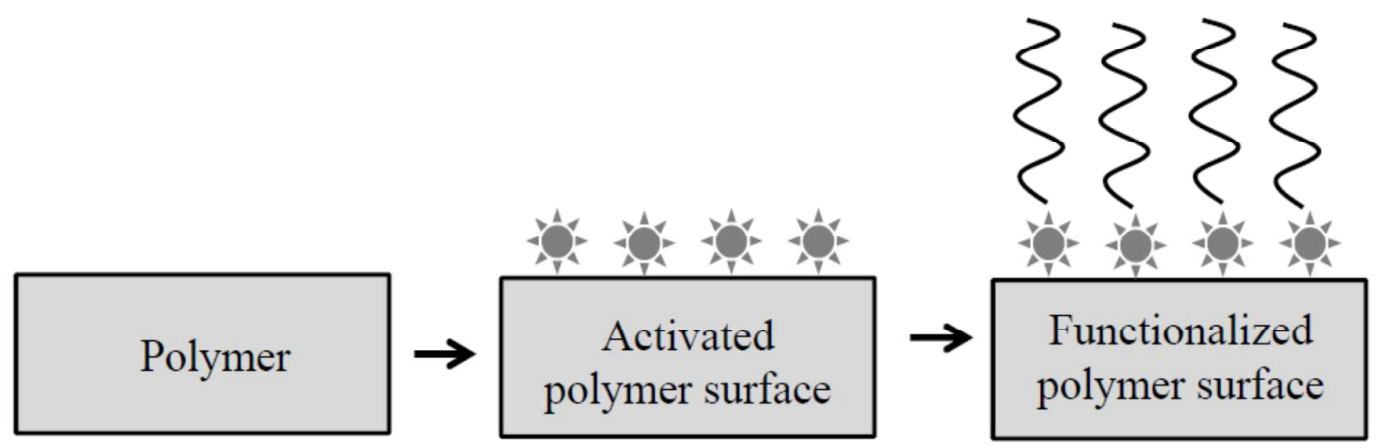

Fig.1. A schematic representation of surface modification

\section{Experimental}

\subsection{Plasma system}

The plasma system used for surface activation is a diffuse coplanar surface barrier discharge (DCSBD) (manufactured by Roplass s.r.o., Brno, Czech Republic). The DCSBD plasma panel consists of two sys- 
tems of parallel strip-like electrodes (with typical dimensions of: $1.5 \mathrm{~mm}$ wide, $\sim 0.5 \mathrm{~mm}$ thick, $1 \mathrm{~mm}$ strip to strip) embedded in aluminium oxide matrix. The thickness of the ceramic layer between the plasma and electrodes is typically $0.4 \mathrm{~mm}$. The plasma is ignited with sinusoidal high frequency, 10$20 \mathrm{kHz}$, high voltage with peak-to-peak values of up to $20 \mathrm{kV}$. The elementary discharge consists of a diffuse surface discharge developed over the electrodes and of a filamentary streamer discharge created between the electrodes giving its $\mathrm{H}$ shape [35]. Visually homogenous plasma can be attained with increasing voltage and absorbed power as more and more elementary discharges are generated. Due to the applied high voltage, heating of the dielectric surface is expected, as well as that of the surrounding gas. To keep the system at the lowest possible temperature with a simple cooling system, oil is circulated over the system, which makes possible to keep the gas temperature around $370 \mathrm{~K}$ [26]. The discharge in the present study was operated in air at $300 \mathrm{~W}$, which provided a quasihomogeneous diffuse plasma surface.

\subsection{Sample preparation and surface treatment}

All experiments were performed on PMMA discs with dimensions of $1 \mathrm{~cm}$ of diameter and $2 \mathrm{~mm}$ of thickness. The discs were cut off from extruded PMMA sheet produced by Quatroplast Ltd. (Hungary). The surface of the sheets was covered by a foil which was removed after cutting. Samples were then washed with water containing $1 \mathrm{wt} \%$ detergent for $5 \mathrm{~min}$ and rinsed successively with deionized water for another 5 min using an ultrasonic cleaner. Finally, the samples were dried and stored at ambient conditions. After this procedure one side of the samples were treated with DBD plasma for 3 min. A constant distance of $0.5 \mathrm{~mm}$ was kept between the DBD surface and the polymer sample disc, while the latter was constantly moved on the top of the DBD unit. After plasma treatment the activated PMMA samples were coated with polyvinylpyrrolidone $\left(\left(\mathrm{C}_{6} \mathrm{H}_{9} \mathrm{NO}\right)_{n}\right.$, PVP10, Sigma-Aldrich, average mol wt 10000) and tannic acid $\left(\mathrm{C}_{76} \mathrm{H}_{52} \mathrm{O}_{46}\right.$, TAN, ACS reagent, Sigma-Aldrich) by the layer-bylayer technique using the dip-coating method. For this purpose $1 \mathrm{wt} \%$ solution from PVP and TAN were prepared. After plasma treatment the samples were put into a continuously shaken PVP solu- 
tion. After 1 hour of soaking the samples were washed with distilled water for 2 minutes, dried at $70^{\circ} \mathrm{C}$ for 10 minutes and placed into TAN solution for another hour. These steps were repeated five more times to reach a targeted 6 PVP-TAN double layers. One sample was prepared for reference. After activation one drop of PVP solution was put onto the surface to establish reaction between the activated surface and the macromolecule. Before measurements all samples were cleaned by rinsing it in distilled water from un-reacted macromolecules.

Table 1

Conditions for sample preparation

\begin{tabular}{|c|c|c|}
\hline Sample ID & Plasma treatment & Staying in reagent \\
\hline PMMA & - & - \\
\hline PMMA-DBD & $3 \mathrm{~min}$ & 1 drop PVP \\
\hline PMMA-PVP & $3 \mathrm{~min}$ & PVP and TAN for 1-1 hour, repeated 6 times \\
\hline PMMA-PVPTAN & $3 \mathrm{~min}$ & \\
\hline
\end{tabular}

\subsection{Surface characterization}

The chemical, morphological and energetic properties of the surface were determined by Attenuated total reflection - Fourier transform infrared spectroscopy (ATR-FTIR), X-ray photoelectron spectroscopy (XPS), atomic force microscopy (AFM) and contact angle measurements. The chemical reaction occurred between PVP and TAN was revealed by ${ }^{1}$ HNMR spectroscopy.

Contact angles were measured by the static sessile drop method at room temperature using double distilled water and diiodomethane (Sigma-Aldrich, Reagent Plus 99\% grade), applying the SEE System apparatus (Advex Instruments, Czech Republic). A Hamilton syringe was used to inject $2 \mu$ droplets. The calculated contact angles are the average of five measurements, performed always on previously 
non-wetted parts of the samples. The surface free energy and its polar and dispersive components were calculated by the method of Owens and Wendt [36].

Fourier transform attenuated total reflectance infrared spectra (FTIR-ATR) were recorded on the discs in the wavelength range of 4000 and $400 \mathrm{~cm}-1$ in 32 scans, using a Tensor 27 (Bruker) spectrophotometer equipped with a Platinum ATR unit A225. The crystal was made of diamond having refractive index of 2.4. For the background signal the measured medium was air.

X-ray photoelectron spectra were recorded on a Kratos XSAM 800 spectrometer operating in fixed analyser transmission mode, using Mg Ka1,2 (1253.6 eV) excitation. Survey spectra were recorded in the kinetic energy range of $150-1300 \mathrm{eV}$ with $0.5 \mathrm{eV}$ steps. Photoelectron lines of the main constituent elements, i.e., the $\mathrm{O} 1 \mathrm{~s}, \mathrm{~N} 1 \mathrm{~s}$ and $\mathrm{C} 1 \mathrm{~s}$, were recorded by $0.1 \mathrm{eV}$ steps. The spectra were referenced to the $\mathrm{C} 1 \mathrm{~s}$ line (binding energy, $\mathrm{BE}=285.0 \mathrm{eV}$ ) of the hydrocarbon type carbon. A GaussianLorenzian peak shape (70/30 ratio) was used for peak decomposition. Quantitative analysis, based on peak area intensities after removal of the Shirley-type background, was performed by the Kratos Vision 2 and by the XPS MultiQuant programs [37], using experimentally determined photoionization cross-section data of Evans et al. [38] and asymmetry parameters of Reilman et al. [39]. Surface chemical com-positions were calculated by the conventional infinitely thick layer model, where all compo-nents are supposed to be homogeneously distributed within the sampling depth detected by XPS. Layer thickness was calculated by the Layers-on-Plane model [37].

Atomic force microscopy (AFM) measurements were performed in ambient condition, at room temperature, in contact mode using multimode AFM (NanoScope V) (Veeco Instruments, Inc., USA). The following parameters were applied: several different scan areas on each sample, scan size $10 \mu \mathrm{m}$, scan rate $2 \mathrm{~Hz}, 512 \times 512$ pixel images. Silicon nitride cantilevers were used with force constant of $0.12 \mathrm{~N} \mathrm{~m}^{-1}$. The analysis was performed with Nanoscope 7.30 software.

\section{Results and discussion}




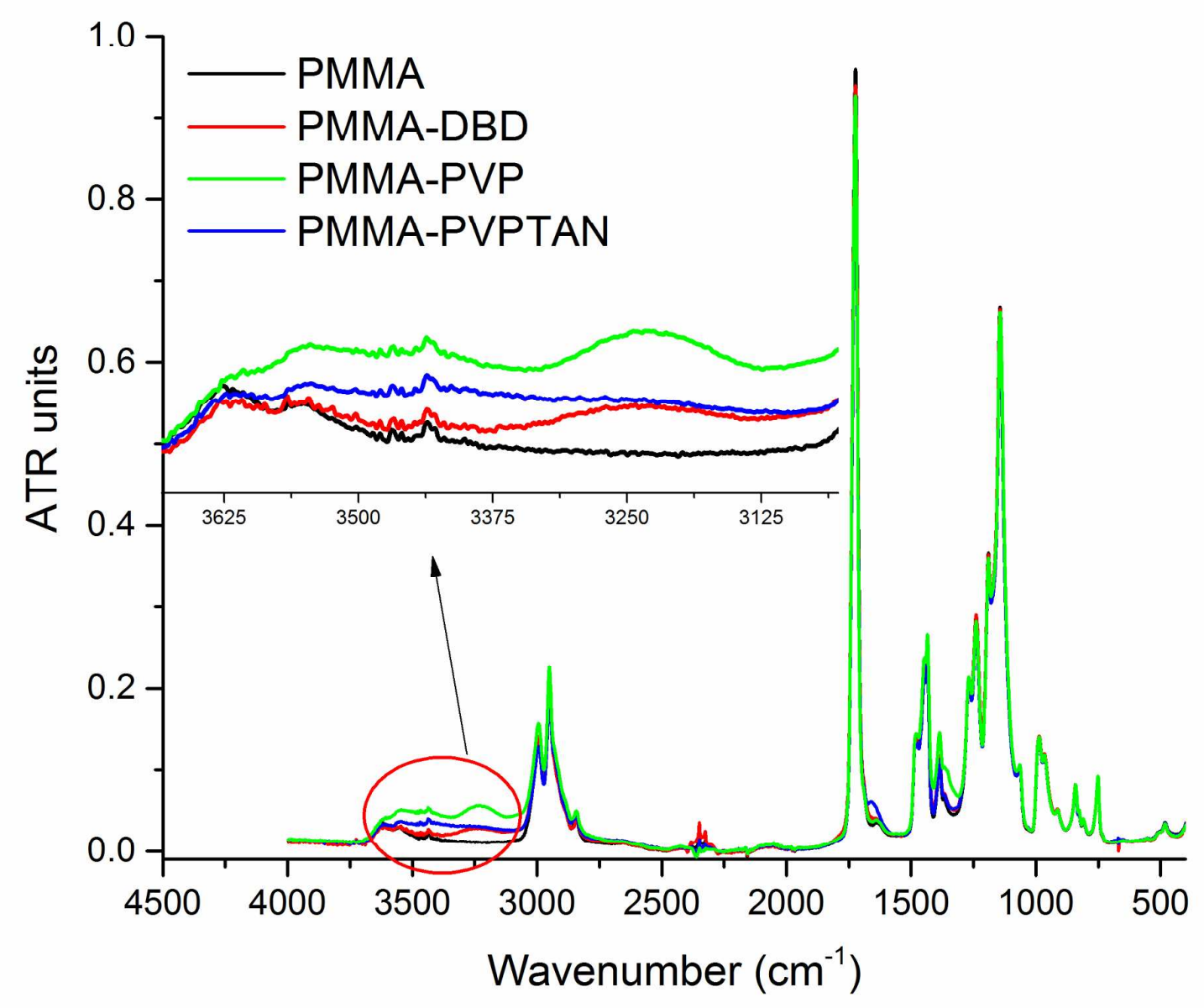

Fig. 2. The infrared spectra of samples

Fig.2. shows the ATR-FTIR spectra of untreated, activated and differently grafted samples. The infrared spectrum indicates group frequencies of the $\mathrm{C}-\mathrm{C}$ and $\mathrm{C}-\mathrm{H}$ groups of the backbone chain, the $\mathrm{C}-\mathrm{C}$, $\mathrm{C}=\mathrm{O}$ and $\mathrm{C}-\mathrm{O}$ units of the ester group and the $\mathrm{C}-\mathrm{H}$ units of the methyl substituent [40] that are typical for PMMA. (Major infrared bands are as follows: $3000-2800 \mathrm{~cm}^{-1}$ : C-H stretching; 1750 $\mathrm{cm}^{-1}$ : C=O stretching; 1450-1330 $\mathrm{cm}^{-1}$ : O- $\mathrm{CH}_{3}$ bending, $\mathrm{C}-\mathrm{CH}_{3}$ bending; $1260-1150 \mathrm{~cm}^{-1}: \mathrm{C}-\mathrm{O}-\mathrm{C} ; \sim 1150 \mathrm{~cm}^{-1}$ : CO stretching.) 
Most obvious changes in IR spectrum on the effect of plasma treatment occurred in the range of $3620-3125 \mathrm{~cm}^{-1}$ that is magnified in the figure. This absorption interval is attributed to $\mathrm{OH}$ stretching vibrations and suggests an increase of oxygen-containing functionalities on the surface. The grafting process was carried out immediately after activation to avoid post-plasma auto-oxidation [41] and possible hydrophobic recovery [42] that seems to be typical for many polymers after plasma treatment [43].

The IR spectrum of PVP grafted surface shows that the intensity of the broad $\mathrm{OH}$ peak increased further, which could be attributed to the traces of water attached to PVP molecules on the surface. The intensity of this $\mathrm{OH}$ peak slightly decreased after the alternate dipping of the activated surface into PVP and TAN solutions. We assume that a reaction took place between PVP and TAN, and consequently the number of active groups capable to bind water decreased. The reaction between macromolecules of PVP and TAN could not be detected by FTIR as their molecules bind only by strong $\mathrm{H}$ bonds.

3.2 Interaction between PVP and TAN studied by NMR

All phenols including TAN can establish $\mathrm{H}$-bonds with $\mathrm{N}$-substituted amide and this bond is one of the strongest types of $\mathrm{H}$-bond [44]. According to Loomis [45] it was discovered that both soluble and insoluble PVP form stable insoluble complexes with tannins. The tannins form H-bond with the peptide linkages, probably through the peptide oxygen, and with the tannins furnishing the hydrogen. To investigate the possible interactions between PVP and TAN, solution state NMR measurements were carried out. To this study DMSO was used as solvent, because the PVP and TAN precipitate from aqueous solution, which indicates an interaction between these materials. The deposit was dried out and dissolved in DMSO. In the spectrum of the mixture no new signal can be identified, but in the $\mathrm{NH}$ region (8.7-10.3 ppm) sharp signals arise, while in the spectrum of pure PVP these signals are very broad as Fig. 3. shows. This change in the shape of signals indicates strong $\mathrm{H}$-bonded structure. Similar phenomenon can be observed in case of proteins in the amide region. To check the possibility of 
any chemical change $13 \mathrm{C}, 1 \mathrm{H}-13 \mathrm{C}$ single and multiple quantum heteronuclear correlation spectra were recorded. By analysis of these spectra, the chemical change can be excluded. The only possible explanation of the sharpening of the $\mathrm{NH}$ signals is the formation of secondary interaction between PVP and TAN. To prove this assumption 1H-DOSY experiment was carried out. As Fig. 4. shows, the PVP and TAN signals belong to the same diffusion coefficient except of the NH protons. While there is a large difference between the molecular weight of TAN and PVP, the same diffusion coefficient denotes the same molecular size. The larger coefficient of $\mathrm{NH}$ protons can be explained with exchange with water protons, which are also present in the solution. By summarizing the NMR measurements of the solution state we can conclude, that strong secondary interactions evolve between PVP and TAN.

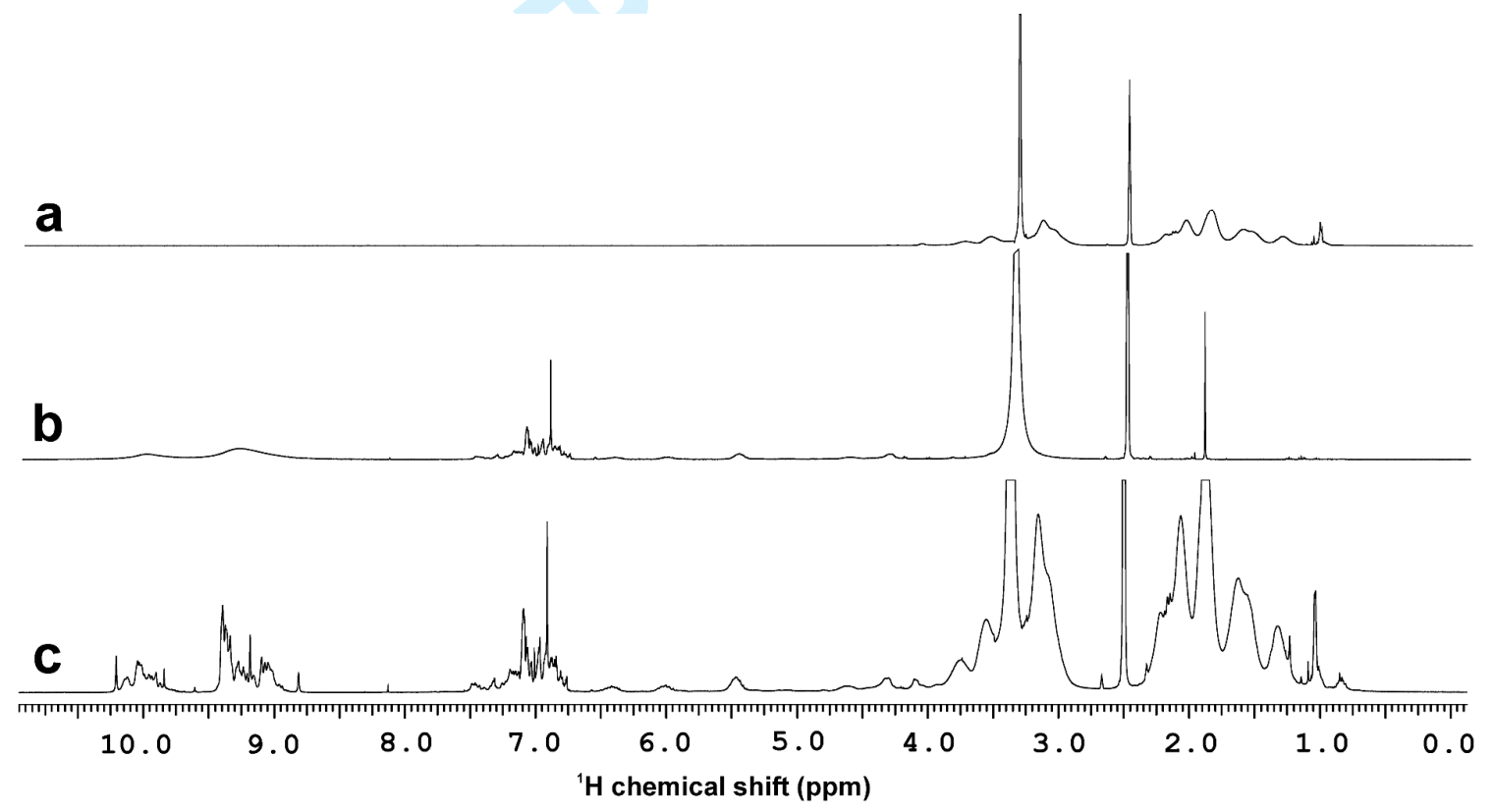

Fig.3. Solution state ${ }^{1} \mathrm{H}$ NMR spectra of PVP (a), TAN (b) mixture (c) in DMSO-d6 on $25^{\circ} \mathrm{C}$ 


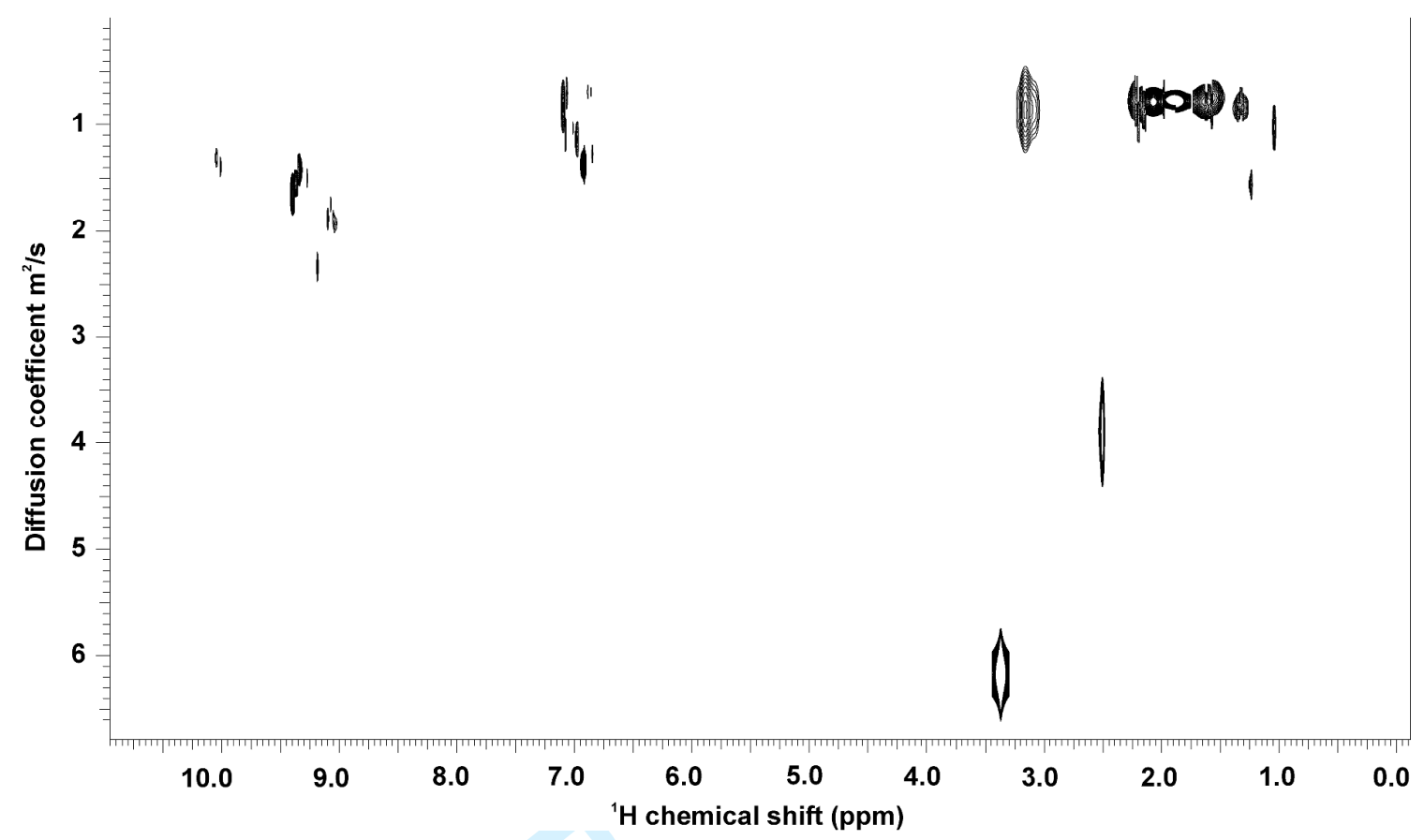

Fig.4. Solution state DOSY spectra of mixture in DMSO-d6 on $25^{\circ} \mathrm{C}$

\subsection{Chemical analysis of the surface}

A more detailed evaluation of chemical composition of the surface was described by XPS analysis. Table 2 compares $\mathrm{C}, \mathrm{N}, \mathrm{O}$ atomic compositions for the samples before treatment and afterwards, while the shapes of the C1s, O1s and N1s photoelectron lines, after various treatments, are shown in Fig.5. 

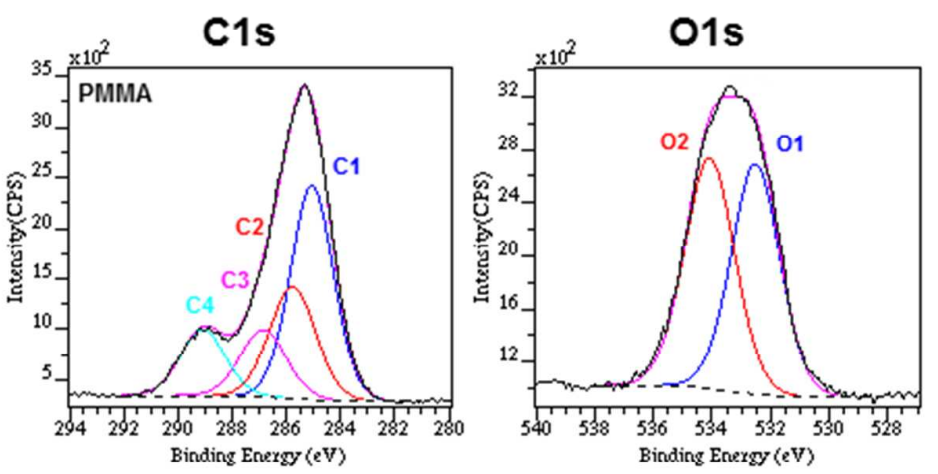

N1s
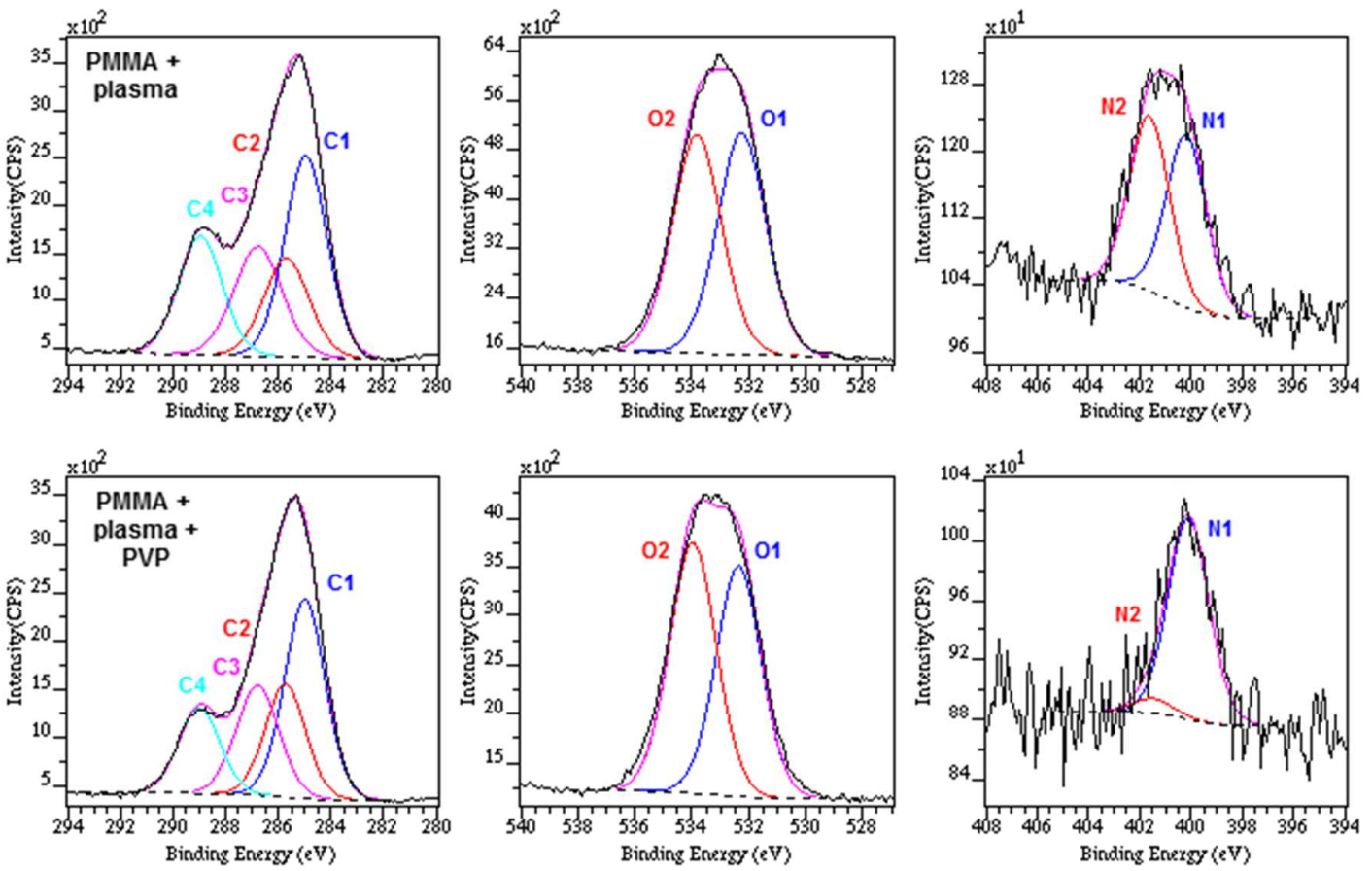

Fig.5. C1s 01s and N1s spectra of PMMA (a), PMMA-DBD (b) and PMMA-PVP (c) samples

Table 2

Surface composition (atomic \%) of the variously treated samples

\begin{tabular}{|c|l|l|l|l|}
\hline Name & Treatment & O & N & C \\
\hline PMMA & Pristine & 20.2 & 0.0 & 79.8 \\
\hline PMMA-DBD & DBD & 29.7 & 2.8 & 67.6 \\
\hline
\end{tabular}




\begin{tabular}{|c|l|l|l|l|}
\hline PMMA-PVP & DBD+PVP & 24.6 & 1.1 & 74.3 \\
\hline PMMA-PVPTAN & DBD+PVP+TAN & 16.4 & 6.5 & 77.1 \\
\hline PMMA & theoretical & 28.6 & -- & 71.4 \\
\hline PVP & theoretical & 12.5 & 12.5 & 75.0 \\
\hline TAN & theoretical & 37.7 & -- & 62.3 \\
\hline
\end{tabular}

The carbon and oxygen components of the pristine PMMA sample (PMMA) correspond to the literature values [46] shown in Table 2. The surface composition is close but not identical to the expected theoretical values (PMMA simulated). The system can be described by a $0.9 \mathrm{~nm}$ hydrocarbon layer on the top of pure PMMA (Fig. 6).

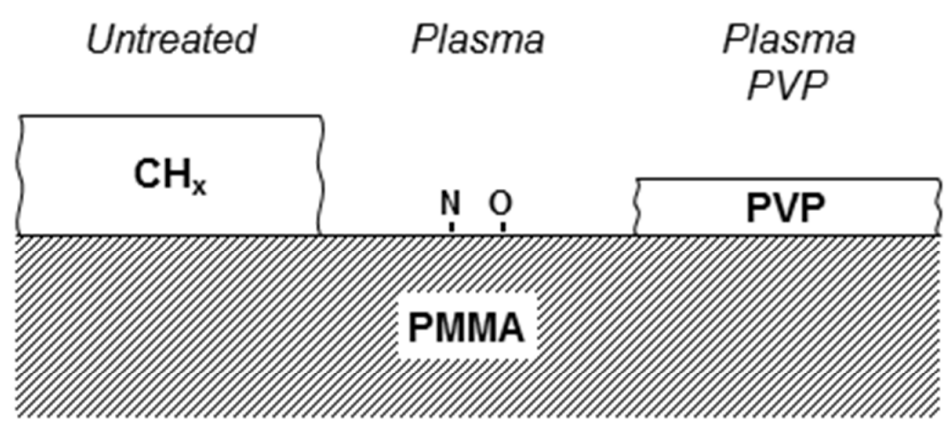

Fig.6. The chemical composition of the top of PMMA according to XPS analysis

The surface treatment of PMMA results in an increase in the $\mathrm{O} / \mathrm{C}$ atomic ratio from 0.25 to 0.44 for $30 \mathrm{~s}$ CSDBD treated sample (PMMA-DBD). The appearance of $\mathrm{N}$ can be attributed to nitrogencontaining groups formed due to the nitrogen content of atmospheric air. The moderate oxygen increase suggests formation of oxygen containing new polar functionalities on the surface layer confirming the results of FTIR spectra. Comparing the C1s spectra (Fig. $51 \mathrm{a}$ and b) of the pristine and 
plasma treated PMMA one can observe the higher intensity of $\mathrm{C} 4$ peak that indicates the increased number of carbonyl $(\mathrm{C}=\mathrm{O})$ groups. The concentration of other oxygen- and nitrogen-containing groups has also increased. This means that air plasma partially removes the hydrocarbon contaminations, and attacks the $\mathrm{C}-\mathrm{C}$ bonds forming nitrogen and more oxygen-containing groups including $\mathrm{C}-\mathrm{O}$, $\mathrm{C}-\mathrm{N}, \mathrm{C}=\mathrm{O}$ on the surface. Introduction of such oxygen-containing groups leads to higher hydrophilicity and/or adhesion of the DBD plasma treated surface.

Applying PVP treatment (PMMA-PVP), the shape of the C1s and 01s did not show large differences, comparing to the PMMA-DBD sample, because the chemical states are quite similar in the PMMA and PVP. In the N1s spectrum the N1 state is dominating, according to the PVP. The measured surface composition can be reasoned by a ca. $0.4 \mathrm{~nm}$ thick PVP layer on the PMMA (Fig. 6). The repeated and alternate exposition of the PMMA to PVP and TAN resulted in increased $\mathrm{N}$ content and lower O content that provide an unambiguous proof for the attachment of PVP and TAN onto the surface.

Table 3

Binding energy $(\mathrm{eV})$ values of the $\mathrm{C} 1 \mathrm{~s}, \mathrm{O} 1 \mathrm{~s}$ and $\mathrm{N} 1 \mathrm{~s}$ photoelectron lines and their assignations in the compounds applied in the experiments. 


\begin{tabular}{|c|c|c|c|c|}
\hline \multirow{2}{*}{ Component } & \multirow{2}{*}{$\begin{array}{c}\text { Binding energy } \\
\text { range }(e V)\end{array}$} & \multicolumn{3}{|c|}{ Assignation } \\
\cline { 3 - 5 } & & PMMA & PVP & TAN \\
\hline C1 & $284.8-285.0$ & C-H & C-H & C-H \\
\hline C2 & $285.5-285.8$ & C-C $=\mathrm{O}$ & C-C $=\mathrm{O}$ & C-C-C \\
\hline C3 & $286.6-286.9$ & C-O & C-N & C-O \\
\hline C4 & $289.0-289.4$ & $\mathrm{O}=\mathbf{C}-\mathrm{O}$ & $\mathrm{O}=\mathbf{C}-\mathrm{N}$ & $\mathrm{O}=\mathbf{C}-\mathrm{O}$ \\
\hline O1 & $531.7-532.6$ & $\mathrm{C}=\mathbf{O}$ & $\mathrm{C}=\mathbf{O}$ & $\mathrm{C}=\mathbf{O}$ \\
\hline O2 & $532.3-534.0$ & $\mathrm{C}-\mathbf{O}$ & & $\mathrm{C}-\mathbf{O}$ \\
\hline N1 & $400.1-400.2$ & $(\mathrm{C}-\mathbf{N}-\mathrm{C})$ & $\mathrm{C}-\mathbf{N}-\mathrm{C}$ & \\
\hline N2 & $401.1-401.7$ & $\left(-\mathbf{N O}, \mathbf{N}^{+}\right)$ & & \\
\hline
\end{tabular}

\subsection{Contact angle measurements}

Contact angle measurements are commonly used to evaluate the hydrophilicity of polymer surfaces.

Contact angles $\Theta_{\mathrm{w}}$ and $\Theta_{\mathrm{DM}}$ measured with water and diiodomethane, respectively, and the calculated values of the total surface energy $\gamma_{\text {tot }}$, as well as its polar $\gamma_{\text {pol }}$ and dispersive $\gamma_{\text {disp }}$ components are tabulated in Table 4. It can be seen that plasma treatment resulted in significant decrease in the contact angles, whilst the total surface energy, as well as its polar and dispersive components increased. In particular, the polar component doubled and the dispersive component increased by ca. $5 \%$. It suggests that the increase in surface energy can be attributed to the appearance of hydrophilic polar groups. The low standard deviation of contact angles is an indication of the homogeneity of the CSDBD treatment. Fig. 7. shows the water contact angle values with respect of treatment time. It is clearly seen, that there is a sudden drop in the contact angle even after a few seconds' treatment but longer treatment time resulted in no further considerable decrease. Similar findings were reported for plasma treatment of various types of polymers $[8,47,48]$. 


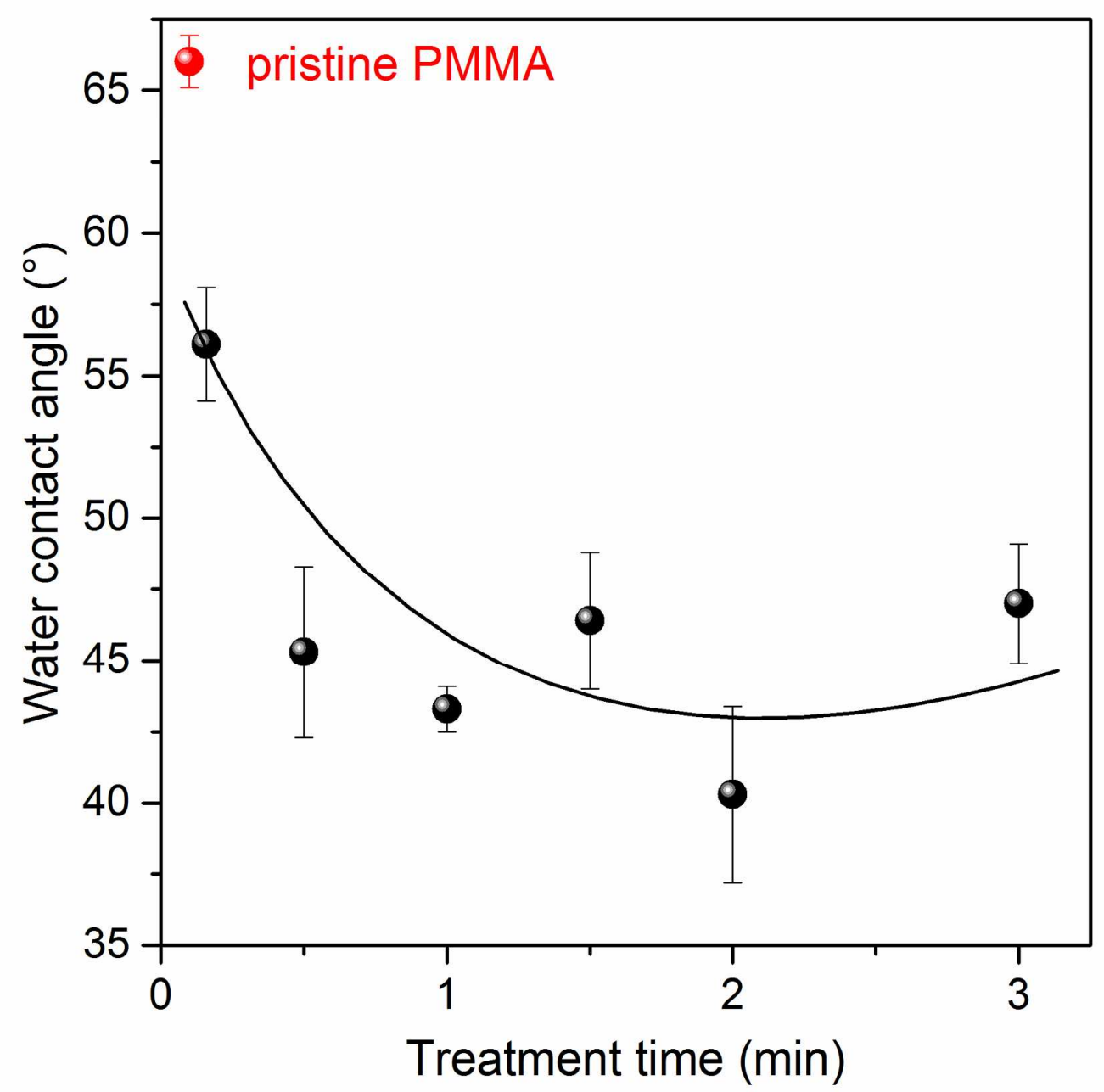

Fig.7. Water contact angle of PMMA in the function of time

After exposition of the plasma treated PMMA to PVP and PVP-TAN macromolecules the hydrophilic nature has not increased further. On the contrary, it decreased along with the surface energy. The restored surface energy suggests that PVP and TAN molecules interact with the PMMA surface and with one another by $\mathrm{H}$ bonds and there is no room left for novel $\mathrm{H}$ bonds on the outer layer.

Table 4

Contact angles, surface energy and its components for the samples 


\begin{tabular}{|c|c|c|c|c|c|}
\hline Sample & $\Theta_{\mathrm{w}}(\mathrm{deg})$ & $\Theta_{\mathrm{DM}}(\mathrm{deg})$ & $\gamma_{\mathrm{pol}}\left(\mathrm{mJ} / \mathrm{m}^{2}\right)$ & $\gamma_{\text {disp }}\left(\mathrm{mJ} / \mathrm{m}^{2}\right)$ & $\gamma_{\text {tot }}\left(\mathrm{mJ} / \mathrm{m}^{2}\right)$ \\
\hline PMMA & $66 \pm 0.9$ & $35 \pm 0.5$ & 8.4 & 42.2 & 50.6 \\
\hline PMMA-DBD & $47 \pm 2.9$ & $29 \pm 1.2$ & 17.4 & 44.8 & 62.3 \\
\hline PMMA-PVP & $63 \pm 2.1$ & $32 \pm 0.8$ & 9.3 & 43.6 & 52.9 \\
\hline PMMA-PVPTAN & $78 \pm 4.4$ & $37 \pm 3.4$ & 3.9 & 41.4 & 45.3 \\
\hline
\end{tabular}

\subsection{Surface morphology}

The wettability of a surface in general is determined not only by the surface chemical functionalities but also by the surface roughness $[49,50]$. Thus the overall wettability can be explained by the competition of two factors: the increase of the roughness and the change of the surface chemical composition. Plasma treatment affects both factors. In addition to the formation of new radicals and functional groups, it also modifies the surface morphology by increasing the roughness [48].

The surface morphology was investigated by AFM to determine the 3D surface topography and calculate the changes in roughness. Fig 8 shows the single line profiles of the samples before and after plasma treatment, and after grafting. The major roughness parameters, including maximum roughness depth $\left(R_{\text {max }}\right)$, root mean square $\left(R_{\text {rms }}\right)$ and mean roughness depth $\left(R_{a}\right)$ obtained from AFM scans regarding a scanning area of $10 \mu \mathrm{m} \times 10 \mu \mathrm{m}$ are tabulated in Table 5. The surface of the pristine polymer (Fig. 8.) is relatively smooth due to the polyethylene foil which protected the surface from scratching: the maximum roughness is quite close to mean roughness. 


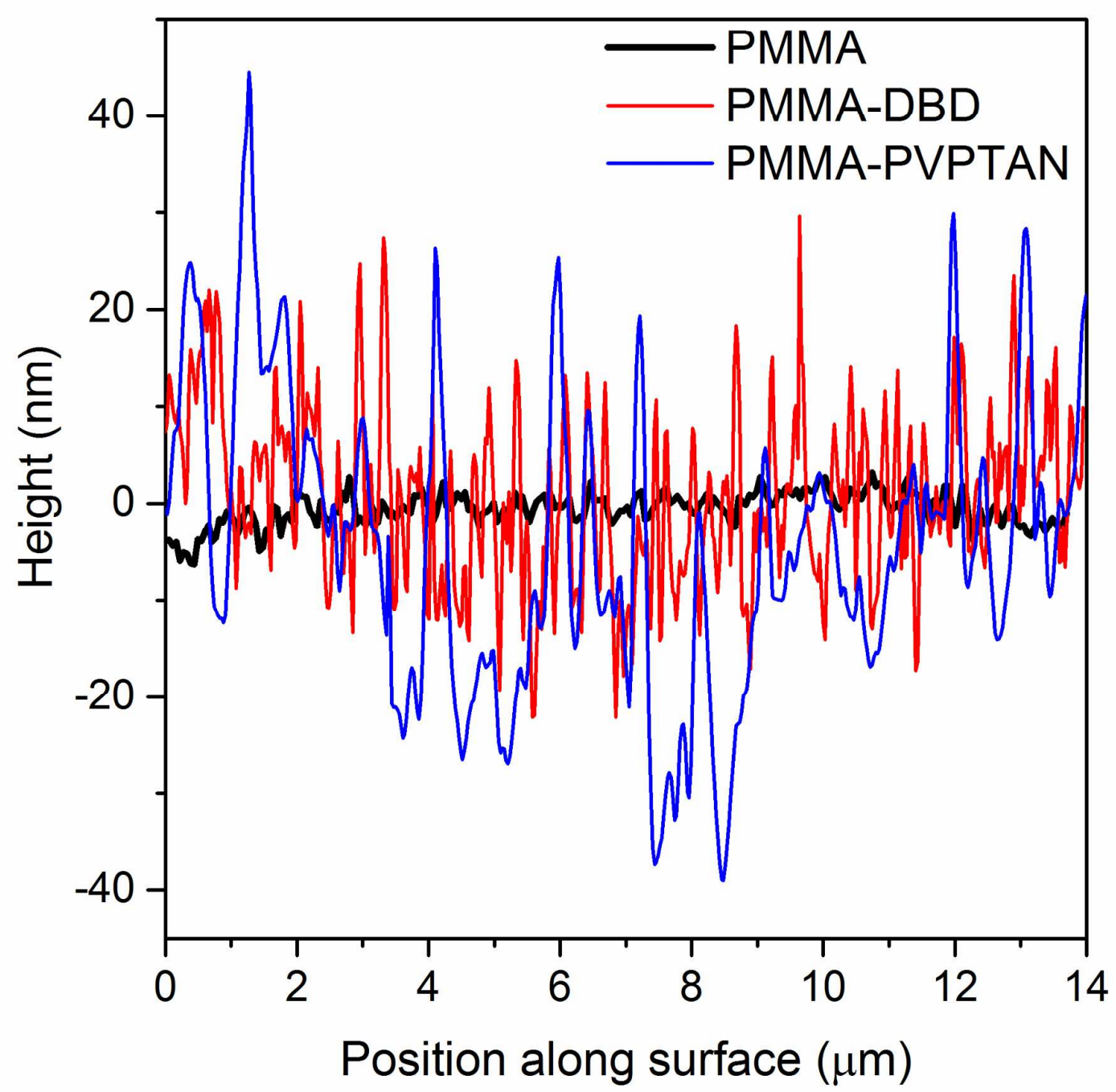

Fig 8 . The AFM surface line scan profiles of the samples (plasma treatment time: $3 \mathrm{~min}$ )

Table 5:

The roughness parameters calculated from line scan profiles

\begin{tabular}{|c|c|c|c|}
\hline Sample & $\mathrm{R}_{\max }(\mathrm{nm})$ & $\mathrm{RMS}(\mathrm{nm})$ & $\mathrm{Ra}(\mathrm{nm})$ \\
\hline PMMA & 6.70 & 1.58 & 3.27 \\
\hline PMMA-DBD & 51.87 & 8.80 & 25.55 \\
\hline
\end{tabular}




\begin{tabular}{|l|l|l|l|}
\hline PMMA-PVPTAN & 82.63 & 16.12 & 39.20 \\
\hline
\end{tabular}

The topography and roughness of the sample after plasma treatment has been significantly changed

(Fig. 9.a and b). Fig. 9.a shows rough morphology with visible hillocks all over the whole surface. During treatment both etching and degradation take place on the PMMA surface due to breaking of chemical bonds on the effect of the energetic active species of the plasma. Formation of low molecular weight oxidized materials (LMWOMs) could also contribute to increased roughness [51]. Attachment of PVP and TAN molecules to the PMMA surface increases the roughness even more (PMMAPVPTAN) since PVP molecules, which get into contact the surface first, attach to the top of the hill like formation increasing its height. Although the peaks become taller, their frequency decreases. This can be attributed to the attached molecules onto the surface, which tend to partially fill up the surrounding deeper valleys.

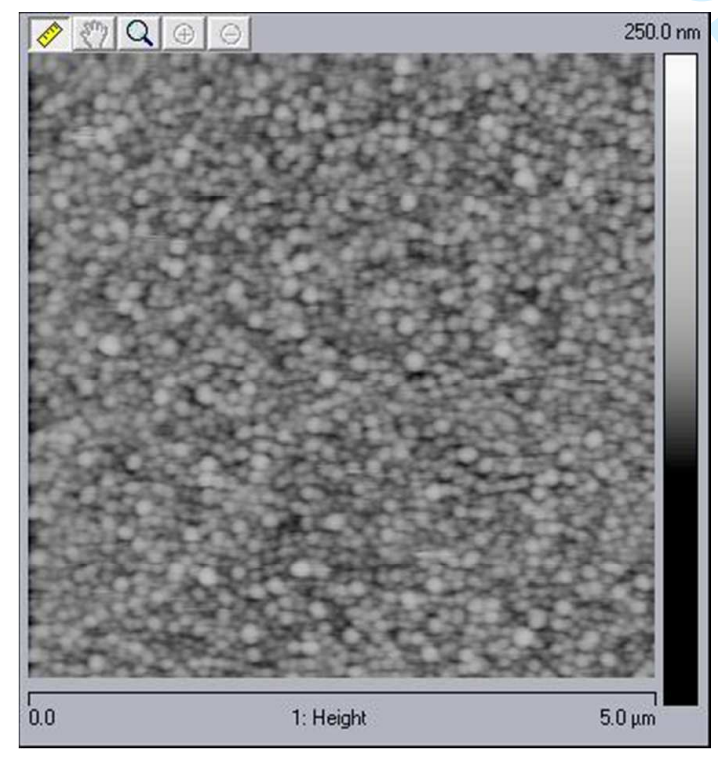

a

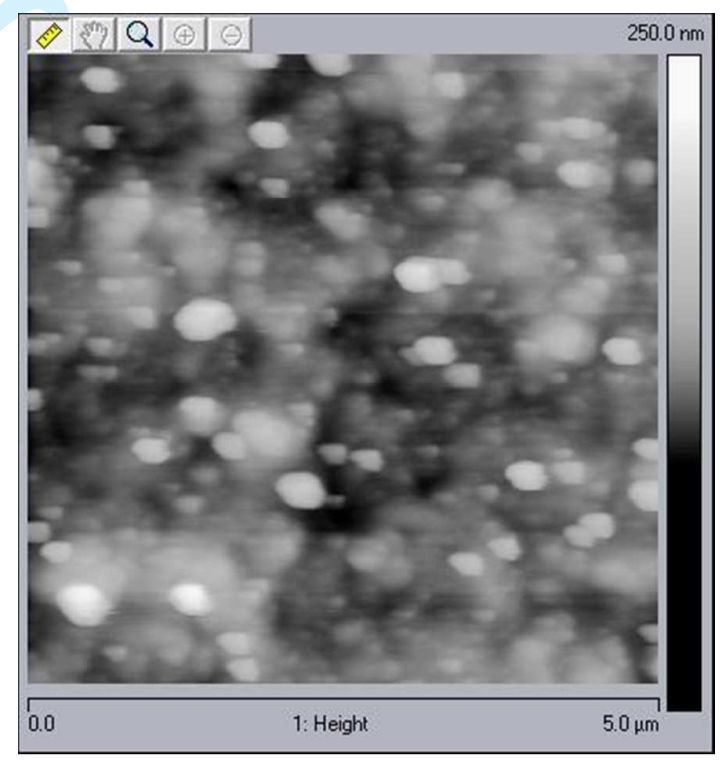

b

Fig 9. AFM topographic maps of PMMA-PVP (a) and PMMA-PVPTAN (b) 
Conclusions

In this work we reported the surface activation of PMMA by air DCSDBD at atmospheric pressure and the subsequent functionalization of the surface by PVP and TAN macromolecules. As an effect of the plasma treatment the $\mathrm{O}$ to $\mathrm{C}$ ratio and the nitrogen content of the topmost surface layer significantly increased according to XPS analysis. These changes imply the increased number of C-O, O-C=O and C$\mathrm{N}$ groups on the surface, which greatly contributed to the higher hydrophilicity of the surface and enabled the attachment of PVP and TAN macromolecules to the activated surface. NMR analysis revealed that between PVP and TAN a strong interaction must be developed by hydrogen bonds. After such functionalization of the surface the surface wettability restored to the original value of the pristine PMMA, however the antimicrobial characteristic of the attached TAN may improve the medical application of the as-treated surface.

Acknowledgement

The authors acknowledge the financial support of NKFIH (No. K104531) and are much obliged to András Tóth for his ideas. A. Domján acknowledges the support of the Bolyai János Research Scholarship.

Table of content

Surface activation polymethyl methacrylate (PMMA) by diffuse coplanar surface dielectric barrier discharge (DCSDBD) plasma unit and subsequent attachment of polyvinylpyrrolidone (PVP) and tannic acid (TAN) macromolecule layers to the surface was studied. Interaction between the two macromolecules was also analyzed by NMR. 


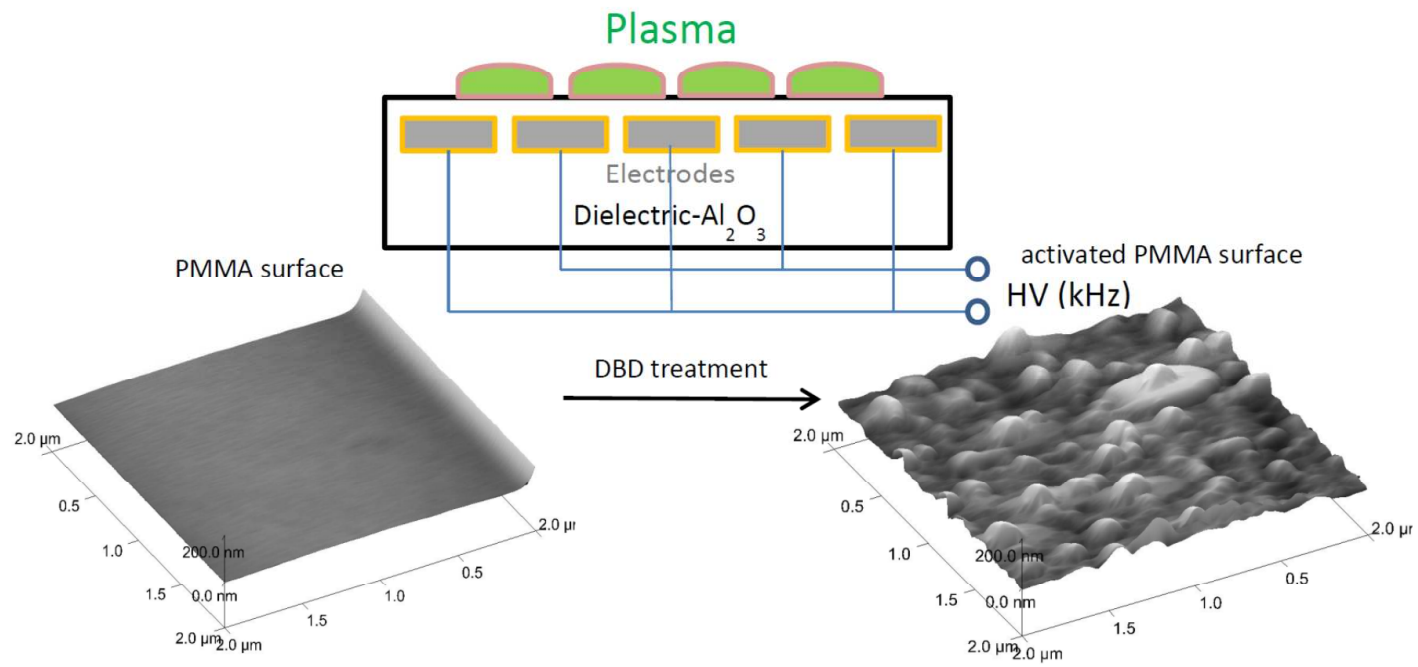

References

[1] J.H. Park, S.H. Lee, K.H. Choi, H.S. Noh, J.W. Lee, S.J. Pearton, Thin Solid Films 2010, 518, 6465.

[2] A. Bettencourt, A.J. Almeida, J. Microencapsul. 2012, 29, 353.

[3] A.M.S. Hamouda, J. Mater. Process. Technol. 2002, 124, 238.

[4]R. Larsson G. Selén, H. Björklund, P. Fagerholm, Biomaterials 1989, 10, 511.

[5] A. Z. Yildirim Bicer, A. Dogan, S. Keskin, O M. Dogan, J. Adhes. 2013, 89, 594.

[6] A.S. Hoffman, J Biomed. Mater. Res. 1986, 20, ix.

[7]H.E. Kaufman, J. Katz, J. Valenti, J.W. Sheets, E.P. Goldberg, Science 1977, 198, 525.

[8] F. Rezaei, B. Shokri, M. Sharifian, Appl. Surf. Sci. 2015, 164, 471.

[9]C. Borcia, I.L. Punga, G. Borcia, Appl. Surf. Sci. 2014, 317, 103.

[10]L. Zhang, D. Wu, Y. Chen, X. Wang, G. Zhao, H. Wan, C. Huang, Appl. Surf. Sci. 2009, 255, 6840. 
[11]S. Patel, R.G. Thakar, J. Wong, S.D. McLeod, S. Li, Biomaterials 2006, 27, 2890.

[12]Y. Wei, Y. Chen, P. Liu, Q. Gao, Y.Sun, C. Huang, Plasma Chem. Plasma Process. 2011, 31, 811.

[13]M. Gilliam, S. Farhat, A. Zand, B. Stubbs, M. Magyar, G. Garner, Plasma Process. Polym. 2014, 11, 1037.

[14]M. Herrero, R. Navarro, Y. Grohens, H. Reinecke, C. Mijangos, Polym. Degrad. Stab. 2006, 91, 1915.

[15]S. Siau, A. Vervaet, E. Schacht, U. Demeter, A. Van Calster, Thin Solid Films 2006, 495, 348.

[16] M. Amirilargani, M. Sadrzadeh, E.J.R. Sudhölter, L.C.P.M. de Smet, Chem. Eng. J. 2016, 289, 562.

[17]T.O. Kääriäinen, S. Lehti, M.-L. Kääriäinen, D.C. Cameron, Surf. Coat. Technol. 2011, 205, 5475.

[18]J. Shin, X. Liu, N. Chikthimmah, Y.S. Lee, Appl. Surf. Sci. 2016, 386, 276.

[19]M. Shahbazi , S.J. Ahmadi, A. Seif, G. Rajabzadeh, Food Hydrocoll. 2016, 61, 378.

[20]P. Favia, R. d'Agostino, Surf. Coat. Technol. 1998, 98, 1102.

[21]S. Yoshida, K. Hagiwara, T. Hasebe, A. Hotta, Surf. Coat. Technol. 2013, 233, 99.

[22]P. Slepička, N. Slepičková Kasálková, E. Stránská, L. Bačáková, V. Švorčík, eXPRESS Polym. Lett. 2013, 7, 535.

[23]P.K. Chu, J.Y. Chen, L.P. Wang, N. Huang, Mater. Sci. Eng. R Rep. 2002, 36, 143.

[24]T. Desmet, R. Morent, N. De Geyter, C. Leys, E. Schacht, P. Dubruel, Biomacromolecules 2009, 10, 2351.

[25] J.M. Goddard, J.H. Hotchkiss, Prog. Polym. Sci. 2007, 32, 698. 
[26] M. Černák, L. Černáková, I. Hudec, D. Kováčik A. Zahoranová, Eur. Phys. J. Appl. Phys. 2009, 47, 22806.

[27] A. Chirokov, A. Gutsol, A. Fridman, Pure Appl. Chem. 2005, 77, 487.

[28] A. Dekker, K. Reitsma, T. Beugeling, A. Bantjes, J. Feijen, W.G. van Aken, Biomaterials 1991, 12, 130.

[29] N.A. Alcantar, E.S. Aydil, J.N. Israelachvili, J. Biomed. Mater. Res. 2000, 51, 343.

[30] Popelka A., Novák I., Lehocký M., Bílek F., Kleinová A., Mozetič M., Špírková M., Chodák I., eXPRESS Polymer Letters, 402, 9, 2015.

[31]A. Tóth, K. Szentmihályi, Zs. Keresztes, I. Szigyártó, D. Kováčik, M. Černák, K. Kutasi, Open Chem. 2015, 13, 557.

[32]H. Akiyama, K. Fujii, O. Yamasaki, T. Oono, K. Iwatsuki, J. Antimicrob. Chemother. 2001, 48, 487.

[33] M. Akagawa, K. Suyama, Eur. J. Biochem. 2001, 268, 1953.

[34]F. Haaf, A. Sanner, F. Straub, Polym. J. 1985, 17, 143.

[35]M. Šimor, J. Ráhel, P. Vojtek, A. Brablec, M. Cernák, Appl. Phys. Lett. 2002, 81, 2716.

[36]D.K. Owens, R.C. Wendt, J. Appl. Polym. Sci. 1969, 13, 1741.

[37]M. Mohai, Surf. Interface Anal. 2004, 36, 828.

[38]S. Evans, R.G. Pritchard, J.M. Thomas, J. Electron Spectrosc. Relat. Phenom. 1978, 14, 341.

[39]R.F. Reilman, A. Msezane, S.T. Manson, J. Electron Spectrosc. Relat. Phenom. 1976, 8, 389.

[40] Infrared Spectroscopy: Fundamentals and Applications, B. Stuart, John Wiley \& Sons, Ltd., 2004. 
[41]J. Friedrich, R. Mix, G. Kühn, „Polymer surface modification with monofunctional groups of different type and density", in Plasma Processes and Polymers, R. d'Agostino, P. Favia, C. Oehr, M.R. Wertheimer Eds., Wiley-VCH, Weinheim, 2005, p. 3-21.

[42]F. Truica-Marasescu, P. Jedrzejowski, M.R. Wertheimer, Plasma Process. Polym. 2004, 1, 153.

[43]E. Bormashenkoa, G. Chaniela, R. Grynyova, Appl. Surf. Sci. 2013, 273, 549.

[44]M.St.C. Flett, J. Soc. Dyers Colourists 1952, 68, 59.

[45]W.D. Loomis, J. Battaile, Phytochemistry 1966, 5, 423.

[46] Beamson G, Briggs D. High resolution XPS of organic polymers - the Scienta ESCA300 database. Chichester, Wiley, 1992.

[47]C. Huang, Y.-C. Chang, S.-Y. W.C. Huang, Y.-C. Chang, S.-Y. Wu, Thin Solid Films 2010, 518, 3575.

[48]Z. Fang, Y. Liu, K. Liu, T. Shao, C. Zhang, Vacuum 2012, 86, 1305.

[49] A. Jordá-Vilaplana, V. Fombuena, D. García-García, M.D. Samper, L. Sánchez-Nácher, Eur. Polym. J. 2014, 58, 23.

[50] A. Sarani, N. De Geyter, A.Yu. Nikiforov, R. Morent, C. Leys, J. Hubert, F. Reniers, Surf. Coat. Technol. 2012, 206, 2226.

[51]K.G. Kostova, T.M.C. Nishime, A.H.R. Castro, A. Toth, L.R.O. Hein, Appl. Surf. Sci. 2014, 367. 314, 


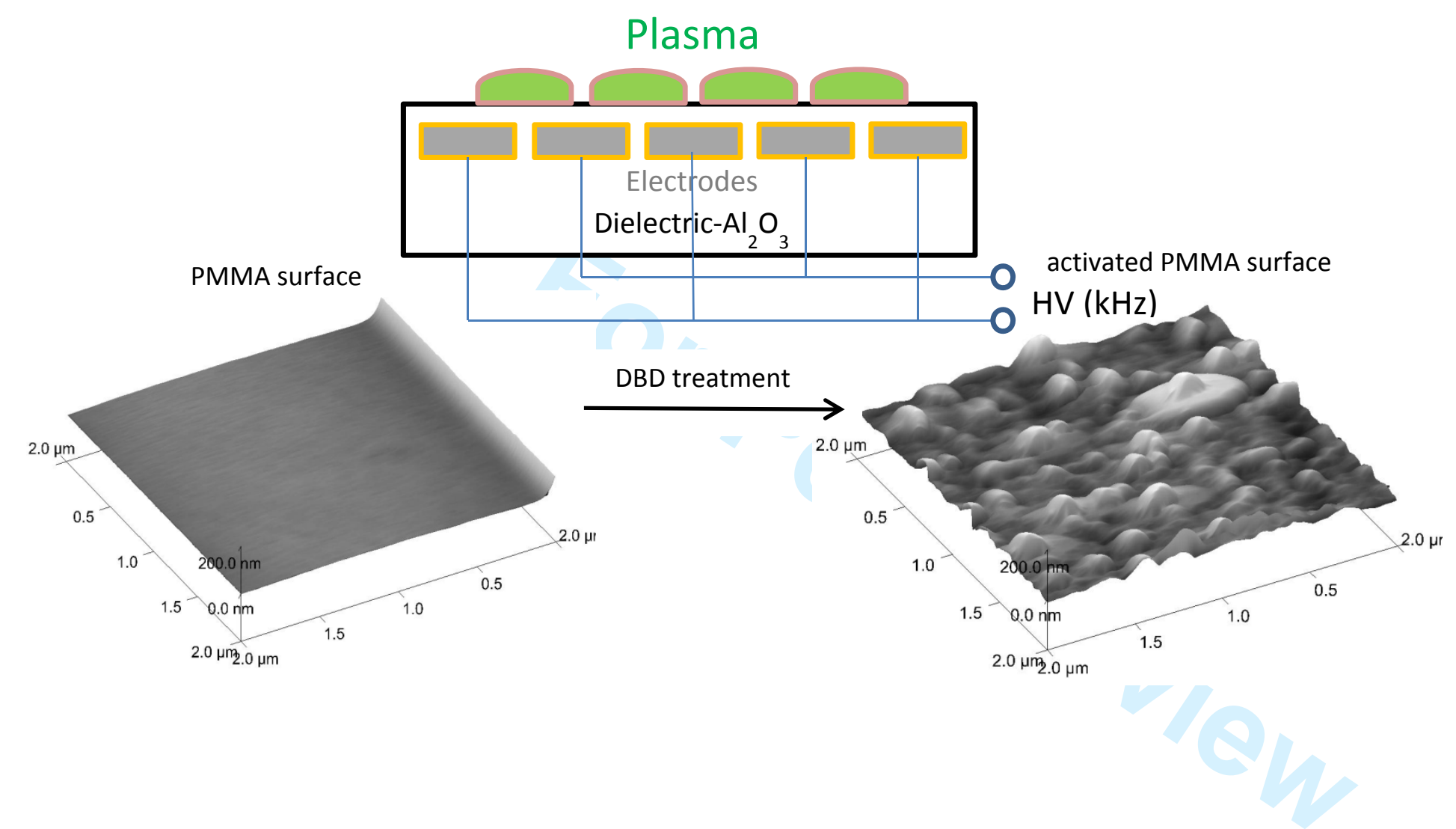




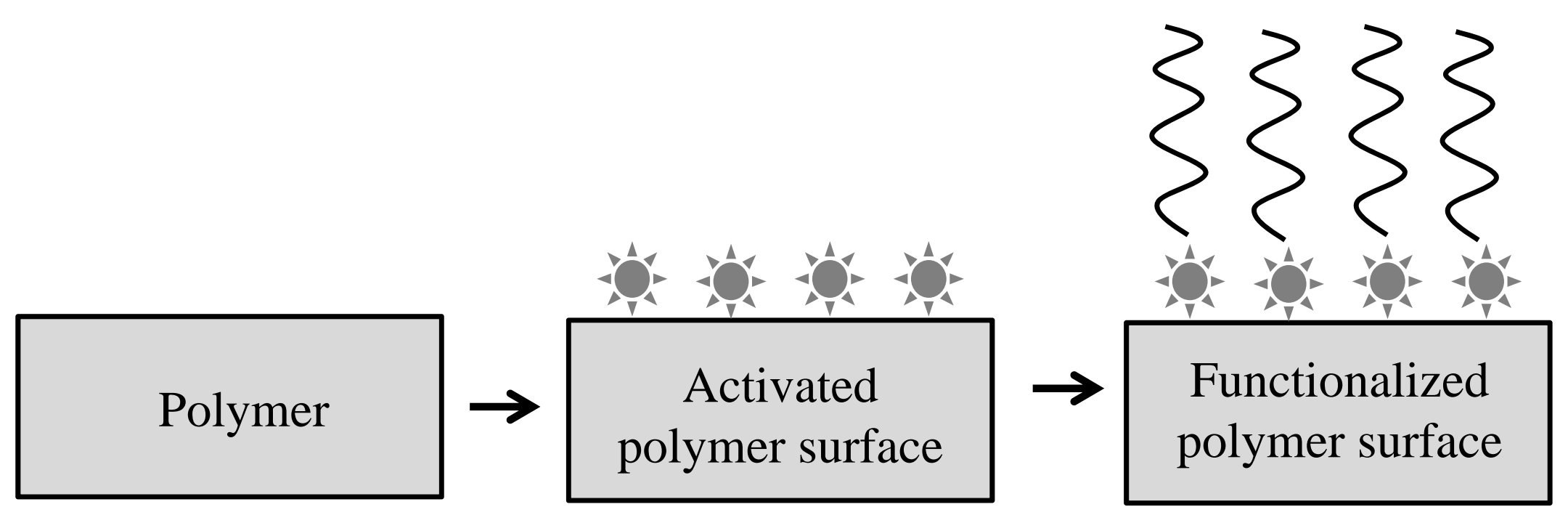




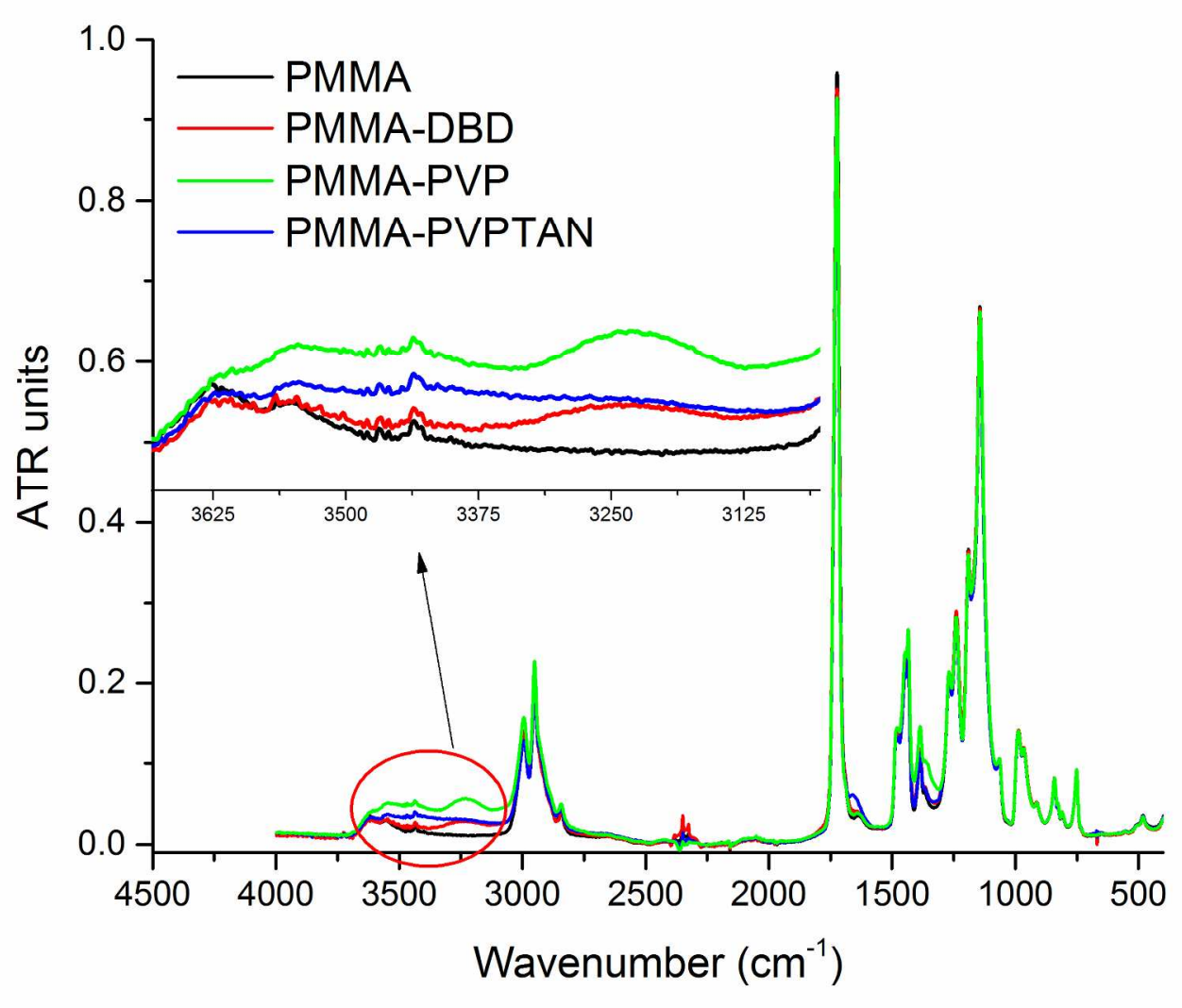

Fig. 2. The infrared spectra of samples $225 \times 192 \mathrm{~mm}(300 \times 300$ DPI $)$ 


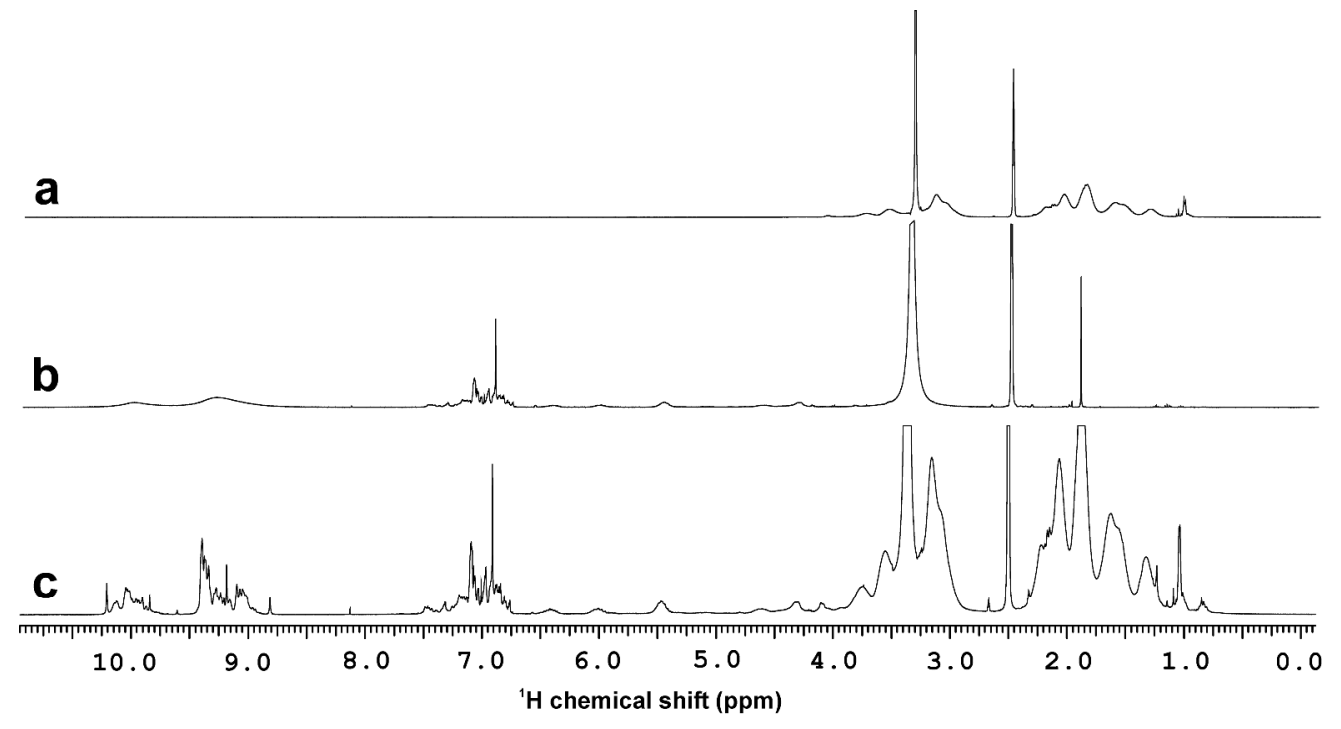

Fig.3. Solution state ${ }^{1} \mathrm{H}$ NMR spectra of PVP (a), TAN (b) mixture (c) in DMSO-d6 on $25^{\circ} \mathrm{C}$ 


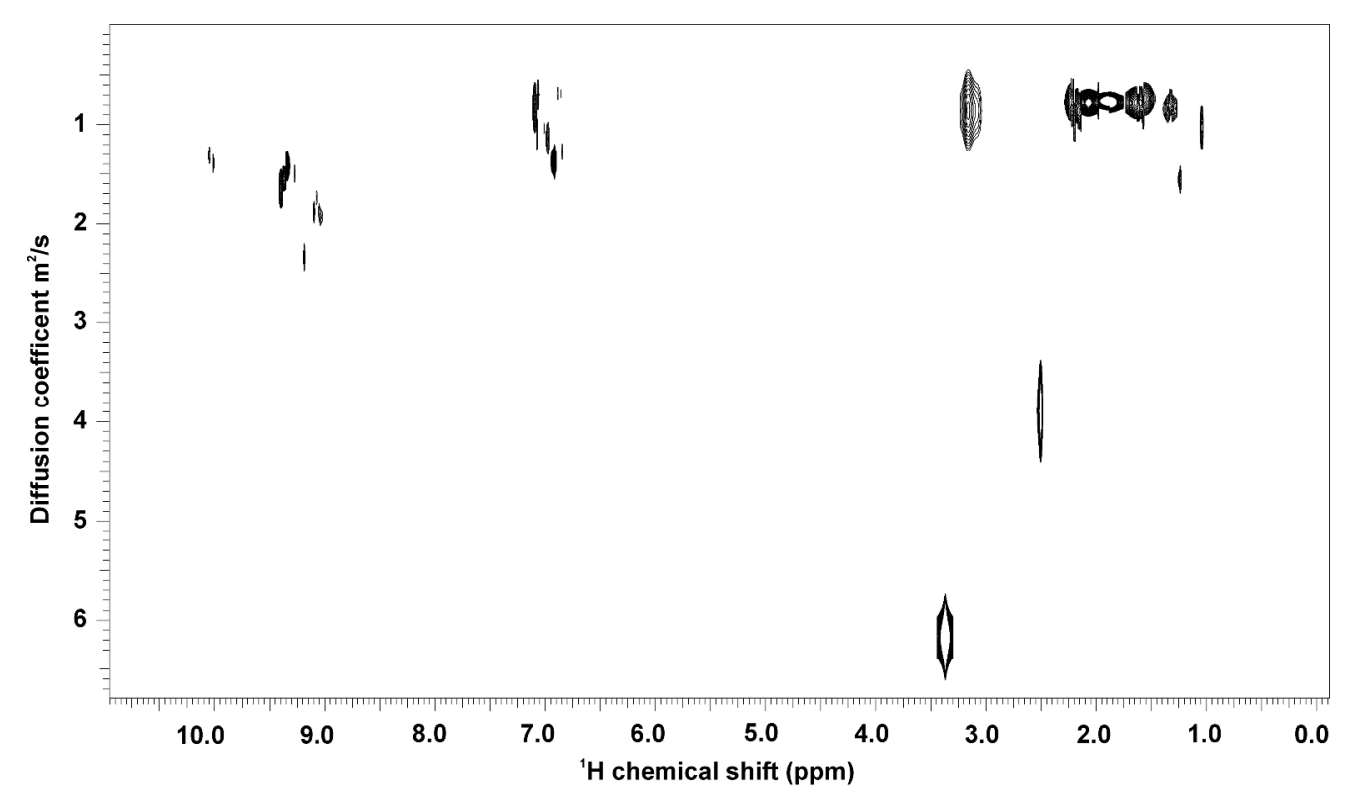

Fig.4. Solution state DOSY spectra of mixture in DMSO-d6 on $25^{\circ} \mathrm{C}$ 

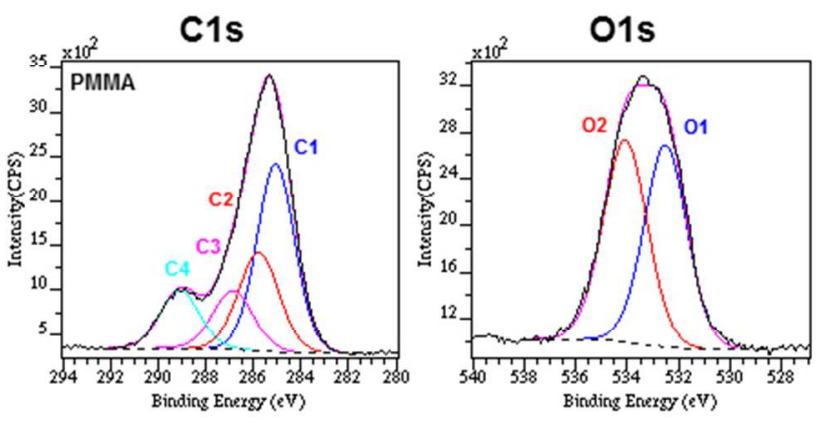

N1s
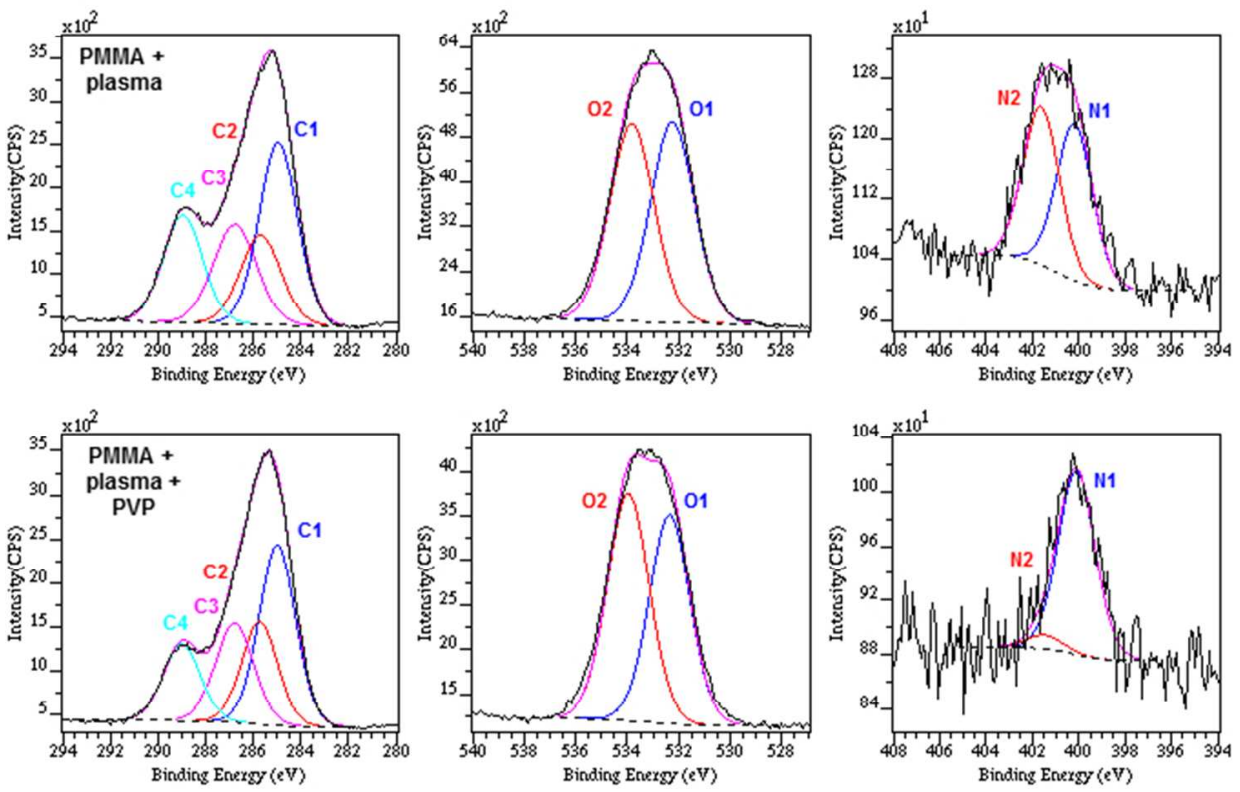

Fig.5. C1s O1s and N1s spectra of PMMA (a), PMMA-DBD (b) and PMMA-PVP (c) samples $189 \times 192 \mathrm{~mm}(96 \times 96$ DPI) 


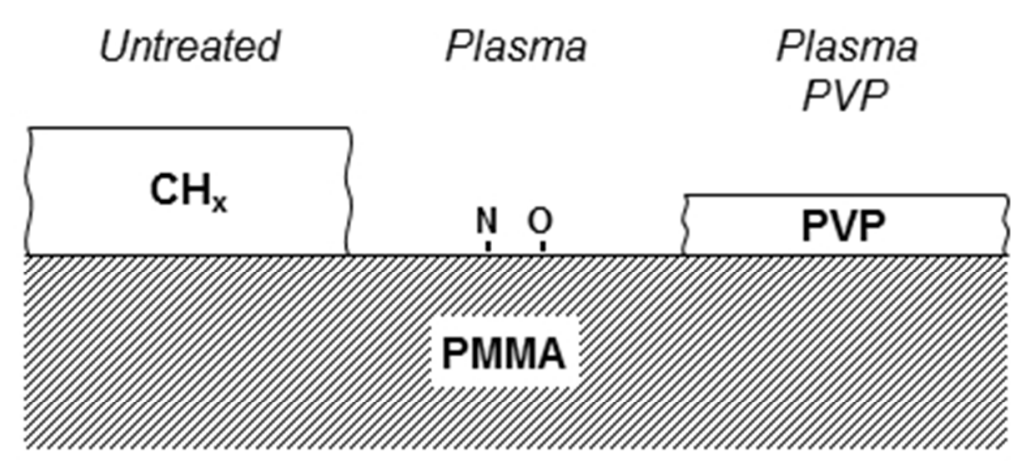

Fig.6. The chemical composition of the top of PMMA according to XPS analysis $120 \times 65 \mathrm{~mm}(96 \times 96 \mathrm{DPI})$ 


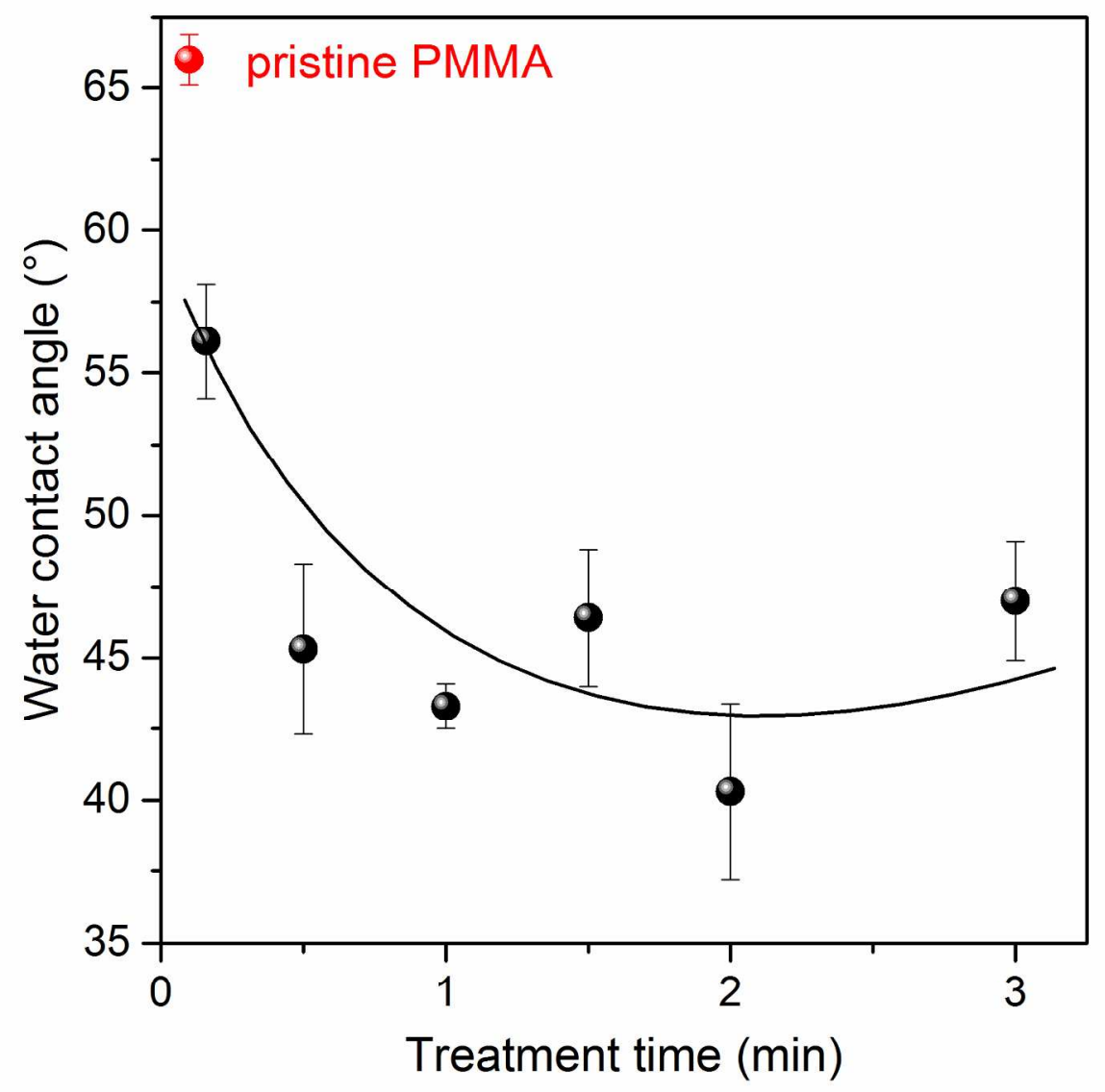

Fig.7. Water contact angle of PMMA in the function of time $206 \times 193 \mathrm{~mm}(300 \times 300$ DPI $)$ 


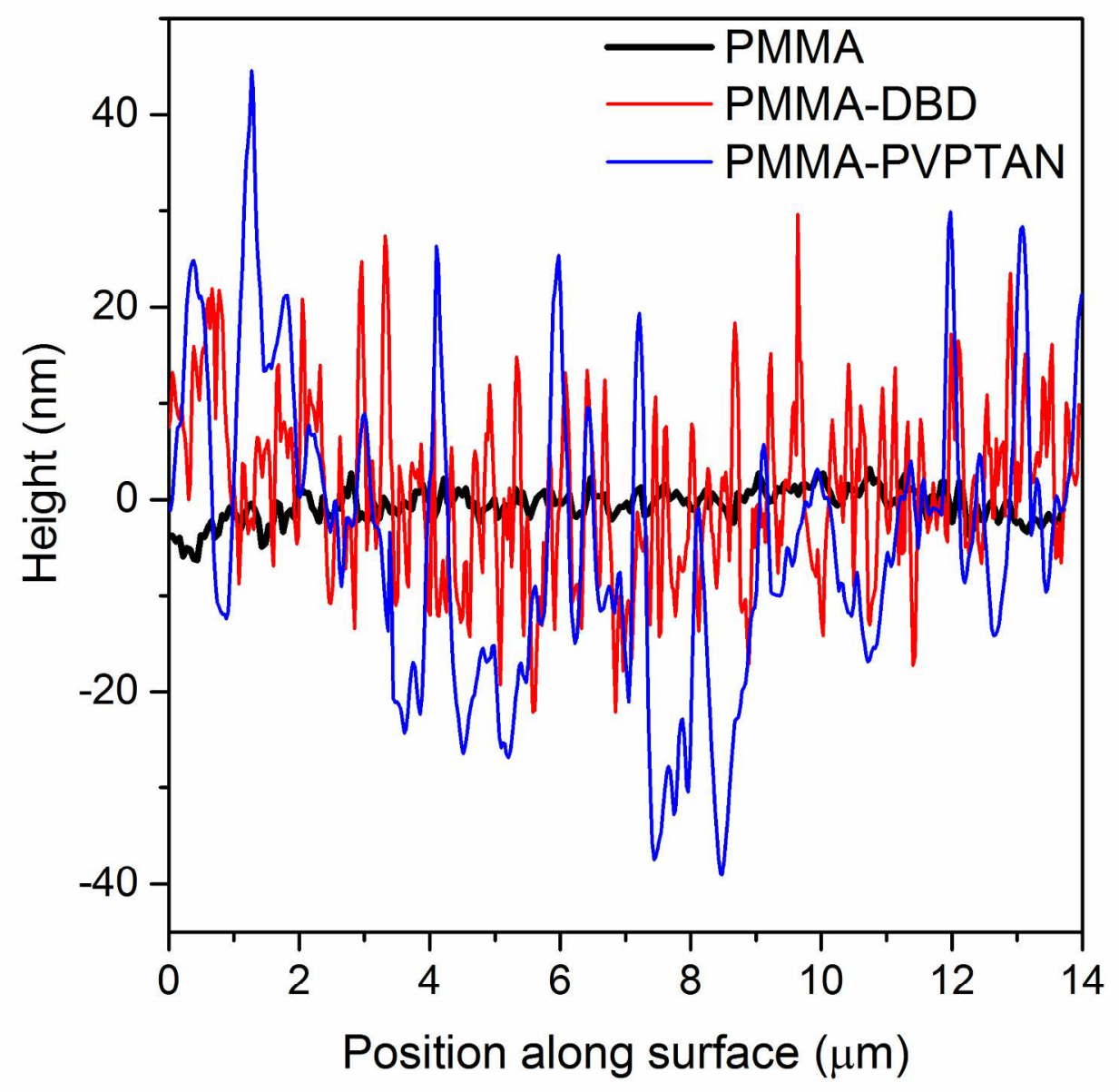

Fig 8. The AFM surface line scan profiles of the samples (plasma treatment time: $3 \mathrm{~min}$ ) $197 \times 191 \mathrm{~mm}(300 \times 300$ DPI $)$ 


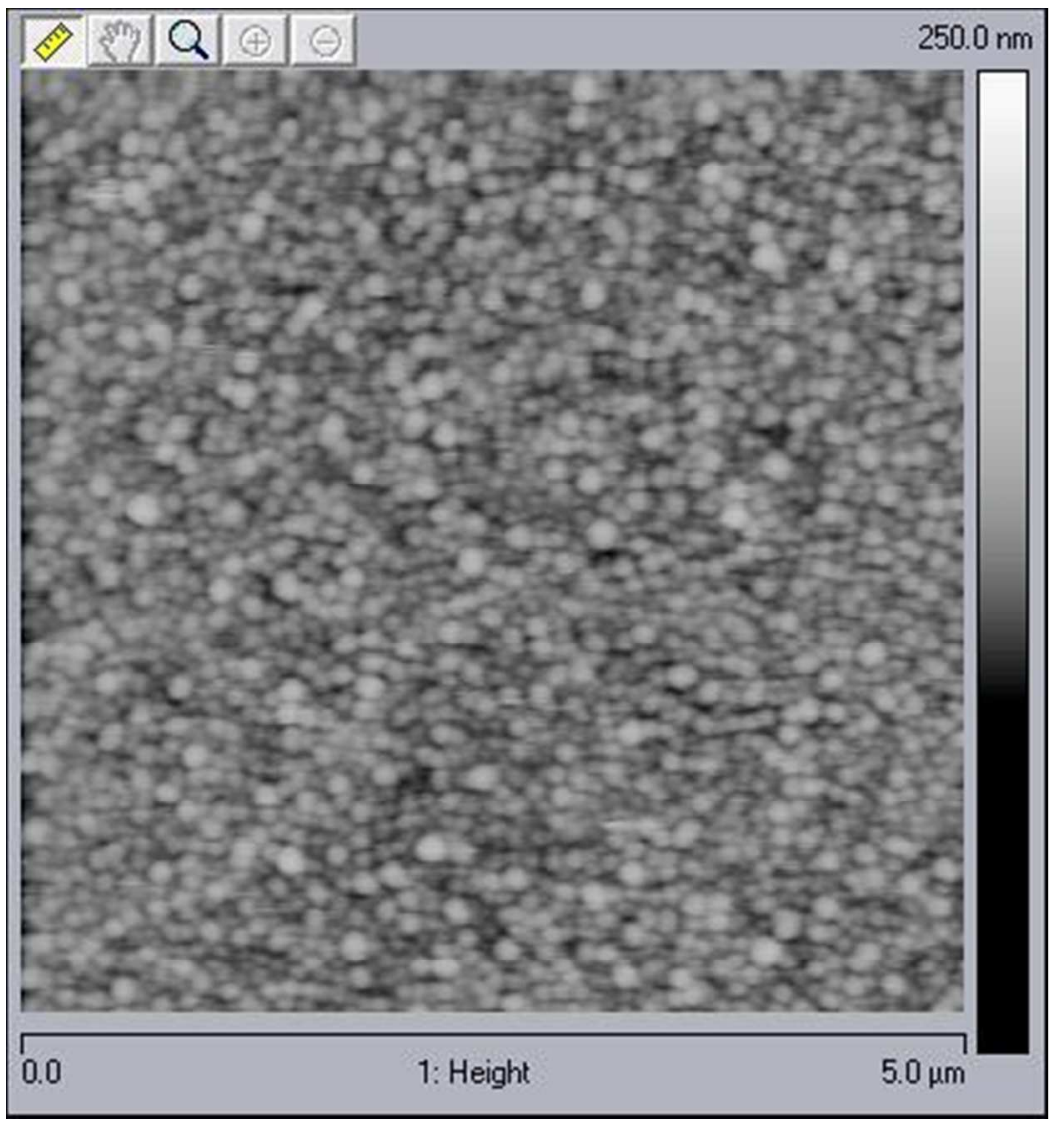

Fig 9. AFM topographic maps of PMMA-PVP (a) and PMMA-PVPTAN (b) $141 \times 150 \mathrm{~mm}(72 \times 72 \mathrm{DPI})$ 


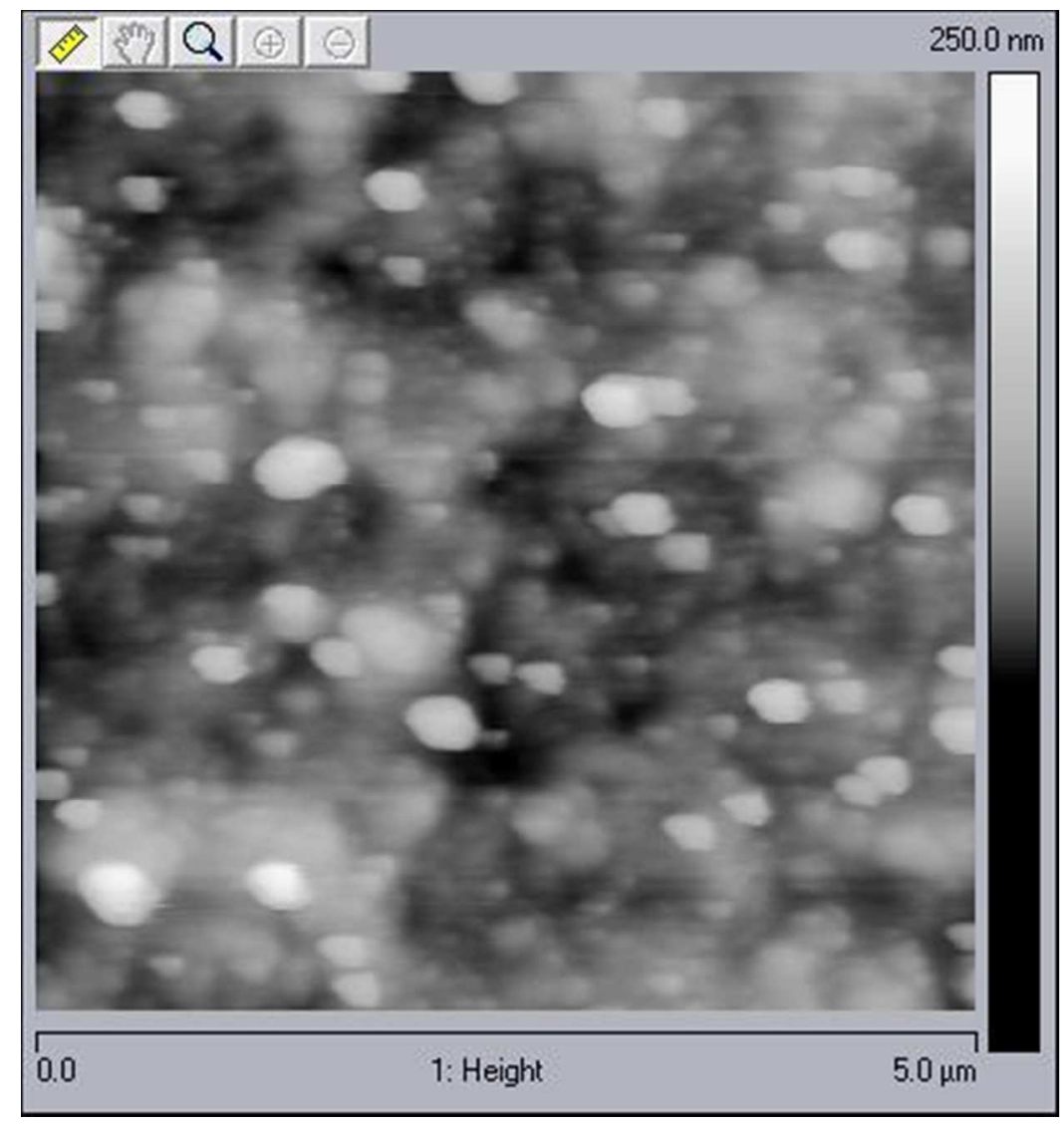

Fig 9. AFM topographic maps of PMMA-PVP (a) and PMMA-PVPTAN (b) $141 \times 150 \mathrm{~mm}(72 \times 72 \mathrm{DPI})$ 